\title{
¿GOBERNABILIDAD O BARBARIE? EL DILEMA FALAZ SOBRE LA REPRESENTACIÓN IGUAL. APUNTES SOBRE IDEOLOGÍA DE LA GOBERNABILIDAD, PROPORCIONALISMO PURO Y CULTURA CONSENSUAL CONSTITUCIONAL
}

\author{
Francisco Palacios Romeo \\ Profesor Titular de Derecho Constitucional, \\ Universidad de Zaragoza
}

Cómo citar este artículo / Citation: Palacios Romeo, F. (2021). ¿Gobernabilidad o barbarie?

El dilema falaz sobre la representación igual. Apuntes sobre ideología de la gobernabilidad, proporcionalismo puro y cultura consensual constitucional.

Palacios Romeo, F. y Cebrián Zazurca, E. (coords.) Elección y representación: una conjunción compleja. Perspectivas y problemas de los regímenes electorales en España, Colección Obras colectivas, Fundación Manuel Giménez Abad, Zaragoza.

DOI: https://doi.org/10.47919/FMGA.OC21.0301

SUMARIO: I. INTRODUCCIÓN - II. EL EJE HISTÓRICO REPRESENTACIÓNGOBERNABILIDAD - 1. Los diferentes modos del paradigma funcionalidadgobernabilidad: s. XIX-XX - 2. La crisis del Estado en el cambio de siglo: ingobernabilidad financista, subordinación institucional y reacción civil-popular III. DEMOCRACIA REPRESENTATIVA PURA Y CANALES PARA EL GOBIERNO INSTITUCIONAL - 1. Democracia representativa pura - 2. Mantra de la ingobernabilidad $v s$. cultura cívica consensual y canales de institucionalidad - IV. CONCLUSIÓN - V. BIBLIOGRAFÍA Y DOCUMENTACIÓN

"One man, one vote" (anónimo, unánime, ¿inánime?) 


\section{INTRODUCCIÓN}

Hay un viejo mantra del derecho constitucional y de la politología por el cual la representación -bajo criterios maximizados de proporcionalidad y deliberacióny el gobierno no son compatibles para poder generar una básica eficacia a los sistemas político-constitucionales. Este mantra decimonónico partía de la negación de la representación igual, y entrado el siglo veinte se estigmatizó el "voto igual" (mismo valor finalista) como un exabrupto populista y se canonizó el "voto plural" (distinto valor finalista) ${ }^{1}$. Este presupuesto conlleva directamente la ruptura del principio de igualdad y de no discriminación. Tal planteo tendría la cobertura de una nueva categoría-teoría: la gobernabilidad.

La gobernabilidad ha conllevado "economía constitucional", en el sentido de como la naturaleza sustancial constitucional, por definición participativo-representativa, se economiza -se reduce- cuando entra en juego la metodología de la gobernabilidad, que siempre argumenta sobre necesidad de "economía de medios políticos" (oligarquía) en la toma de decisiones político institucionales, como único modus de "estabilidad"2.

En principio gobernabilidad sería un concepto amable que alude a que un ente (organización, sociedad, Estado) "pueda ser gobernado"3. Sin embargo, el concepto ha sido expropiado doctrinalmente, y ha pasado a ser sinónimo del axioma "sólo puede ser gobernado de manera institucional y económicamente reduccionista" si se pretende conseguir "estabilidad"; una expropiación terminológica intensiva desde el comienzo de la estrategia de deconstrucción ("crisis") del Estado social ${ }^{4}$, que ha tenido su réplica teórica ${ }^{5}$.

\footnotetext{
${ }^{1}$ Voto igual vs. voto plural. Voto igual, por el que el valor universal del mismo es igual en todas las fases del proceso electivo-representativo, asignándole el mismo valor final a todo ciudadano. Voto plural por el cual el valor del voto es desigual en alguna fase del proceso, ya sea antes de su emisión (censal ipso facto) o después de su emisión (censal ex post facto), asignándole más valor a un ciudadano sobre otro.

${ }^{2}$ La gobernabilidad como término moderno es reciente, pero como concepto es casi antediluviano si reparamos en la utilización combinada de un concepto doctrinal como oligarquía, y de su variante propietarista (plutocracia) que conformaban un sistema ya enunciado por los clásicos. En este sentido Jenofonte (Memorabilia), Platón (La República) o Aristóteles (Política) estaban referenciándose ya en la gobernabilidad como un hipotético fatum político.

${ }^{3}$ La definición pura de la R.A.E. de gobernabilidad, apela a una habilidad, un arte, una situación de estabilidad acordada. Un bien en sí mismo.

${ }^{4}$ Expropiación doctrinal reforzada a partir de su utilización política en el clásico informe a la Comisión Trilateral, por el que el incremento de participación, representación proporcional y consolidación de la demanda (empoderamiento) ciudadano-popular pondría en riesgo la propia 
Este trabajo tiene como fin negar el axioma por el que una representación proporcional pura o igual ("voto igual"), cuando propicia un mapa político más fragmentado, conduce a la ingobernabilidad. Más bien al contrario, es visible en ciclos históricos medios o largos que la estrategia de la gobernabilidad termina produciendo extrema ingobernabilidad, máxime en esas amplias fases de la

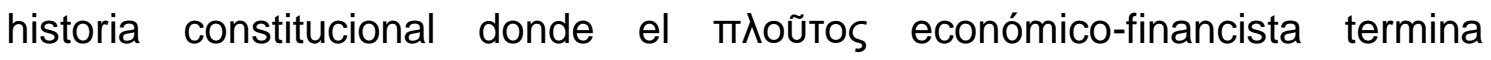
hegemonizando, devaluando y banalizando al $\delta \tilde{n} \mu o s$ político-social. Máxime en un estadio de acopio globalizador de poder que hace al Estado progresivamente más débil, reduciéndolo a una especie de cooperador necesario, constitucionalmente sometido a una evidente heteronomía de su dogmática $^{6}$. En función del planteamiento anterior la hipótesis sintética de este trabajo sería cómo una extensión de la representación igual puede generar a medio plazo mayor estabilidad, bajo los presupuestos de acompañamiento (cultura consensual, arquitectura orgánica) que se señalarán.

Un apunte de método: explicaría poco la relación "gobernabilidad" respecto a fines y funciones constitucionales si aquí se mantuviera una aislada reflexión sobre técnica electoral, voto igual, parlamentarismo negativo y mayoría absoluta o relativa. Por ello las hipótesis se trazarán sobre método holístico, sobre una base previa de naturaleza y fin del Estado (espacio institucional) así como de presupuestos de poder (actores sociales y políticos) ${ }^{7}$.

democracia (Huntington et alts., 1975, The Crisis of Democracy. Report on the governability..."; un tratamiento político estratégico de esta utilización conceptual en Palacios, 1998 a, cap. "El paradigma gobernabilidad: neo-culturalismo...", pp. 316-426). Planteamiento en convergencia con la galaxia neoliberal (Hayek, Bell, Buchanam...). El concepto ha sido utilizado mayoritariamente de manera más mesurada, con tendencia a cuestionar la presente resiliencia del Estado (y por ende del pacto constitucional) ante un advenido nuevo estado de cosas globalizado (cfr., Arbós \& Giner, 1993, "La gobernabilidad...".

5 Este giro en la acepción habría sido replicado por corrientes de teoría crítica. V. gr., la acuñación de un neologismo como gubernamentalidad -a partir de la "gouvernementalité" de Foucault- (Irusta, 2014, "El concepto de gubernamentalidad. La economización...").

${ }^{6}$ El presupuesto de este trabajo sobre la dialéctica gobernabilidad-representación igual tiene su

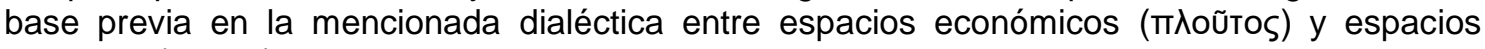

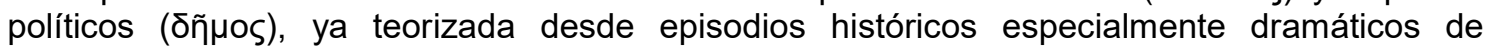
hegemonía financista a comienzos de siglo XX (Heller, 1996, El sentido de la política..."). Ahora, a fecha de también comienzo de siglo, se hace necesario insistir en su actual agudización, que contempla la más "escandalosa reducción del ámbito político" y el apoderamiento "de los centros decisorios por el poder financiero" (De Vega, 1998, "Mundialización y Derecho constitucional...", pp. 13-14, opúsculo de referencia en el desarrollo teórico al respecto).

${ }^{7}$ En función de cómo la perspectiva holística del hecho constitucional -como "pensamiento complejo"- ha ido cediendo un notable espacio, desde la clásica comprehensión relacional de teoría del Estado y derecho constitucional (Jellinek, Laband, Heller...), eludiendo argumentaciones basadas en procesos y etiologías sociales y económicas con actores precisos. Espacios de aprehensión de la realidad espacial que se siguen obviando en la 
Para ello se desarrollan dos líneas de exposición:

I. Una primera parte para trazar un breve eje histórico-político sobre como la gobernabilidad ha sido consustancial al hecho constitucional, ya desde sus orígenes a finales del s. XVIII, donde toda la historia/teoría de la representación estuvo impregnada de dicho ingrediente bajo la coartada de la necesaria funcionalidad. Teoría orgánica del Estado que lo contemplaba como un instrumento elitista con base en el "voto plural desigual", legitimada con base a la presunta falta de capacidad de la "sociedad igual" para asumir tareas de gobierno.

Más bien cíclicamente ha ocurrido lo contrario: la estrategia de la gobernabilidad niega canales para la demanda y la protesta social y, por lo tanto, no habilita espacios institucionales deliberativos proporcionales $\mathrm{y}$, a causa de ello, termina produciendo extrema ingobernabilidad, crisis agudas y, en último extremo, revoluciones. Se hará una síntesis sobre cómo: a) se configura la representación limitada a lo largo del XIX ("sufragio censal liberal/sufragio plural directo, como estructura de extremo conflicto e inestabilidad"); b) en el siglo XX el sufragio universal adquiere un valor representativo relativo a través de tres fases muy distintas ("sufragio universal en valor histórico relativo/voto plural indirecto"); c) en el siglo XXI las sucesivas crisis de sistema producen movimientos sociales de catarsis política, donde una masa crítica notable reivindica una forma de representación más amplia y distinta a través de tres momentos diferenciados ("movilización cívica", "canalización alternativa", "institucionalización").

II. La segunda parte contradice el axioma que enfrenta a gobernabilidad y proporcionalidad igual, a través de la reivindicación de una cultura del consenso y de la estructura de coalición, así como con propuestas sobre canales de institucionalización para la gobernabilidad ("mantra de la ingobernabilidad vs. cultura cívica consensual y canales de institucionalidad"). En la hipótesis ya mencionada que la proporcionalidad igual sumada a cultura del consenso genera gobernabilidad y estabilidad, salvo que dicho sistema de

"decisión" jurisprudencial o doctrinal, en la muy difícil coyuntura histórica actual en donde ya comienza a ser complicada una solución doctrinal clásica "integracionista" (Smend, Heller, Krüger, Hesse...). Una realidad semejante a la de "un derecho constitucional que se mostraba incapaz" en la crisis de entreguerras, y que ahora repite su desconcierto ante un poder fáctico real que adquiere opacidad extrema, con capacidad de agresión normativa constitucional cual "fatal y misterioso acontecimiento de destino" (De Vega, 1998, "Mundialización y Derecho constitucional...", pp. 47, 34). 
institucionalización democrática reciba desde el entorno societario de poder sabotajes insuperables políticos (filibusterismo institucional) o económicosociales (filibusterismo societario).

En primer lugar, se revisita la temática de la representación no proporcional (voto desigual indirecto), valorando: a) carácter de discriminación radical, desproporcionalidad electoral ("discriminación ideológica ex post acto"); b) la consecuencia cuantitativa en valor del voto desigual, y la consecuencia cualitativa en opciones políticas erradicadas ("desvalorización y lapidación de alternativas políticas"); c) propuestas de técnica de voto igual y de reajuste institucional ("elementos técnicos para el voto universal real").

En segundo lugar, se abordan las tres críticas tópicas en contra de la proporcionalidad igual: a) la perturbación que causan procesos electorales continuados de índole técnica y económica; b) la dificultad para obtener investiduras del ejecutivo, con un coste de parálisis técnico-política, tanto del Estado como del país; c) la subsiguiente dificultad legislativa derivada de los débiles y fragmentados apoyos del gobierno; d) la añadida dificultad para habilitar/designar cargos institucionales de control.

Frente a estas posiciones actuales favorables a una gobernabilidad infra representada se propondrá: a) cultura del consenso ("ley de proporcionalidad de Gamson"); b) potencial asunción de técnicas de parlamentarismo inverso ("opción del parlamentarismo negativo de mayoría relativa"); c) mecánicas legislativas funcionales ("opción de mayoría legislativa relativa"); d) cambio en la designación de las instituciones de control ("extracción proporcional pura").

\section{EL EJE HISTÓRICO REPRESENTACIÓN-GOBERNABILIDAD}

\section{Los diferentes modos del paradigma funcionalidad-gobernabilidad: s. XIX-XX}

A) Siglo XIX: representación minimalista censal liberal como estructura de conflicto, inestabilidad y quiebra constitucional

Se puede partir de una primera tesis de tipo histórico: el sistema de representación liberal -minimalista por censal- fue un estadio de conflicto, inestabilidad e ingobernabilidad. Sistema que, por definición, -en la lógica de la gobernabilidad- debía facilitar la gestión de gobierno al ser unos pequeños 
grupos de grandes propietarios y de nobleza aggiornada los destinados a votar y ser votados en sistemas habitualmente de circunscripción única y de turno pactado. Conformar mayorías y componer gobiernos debería haber sido así extremadamente fácil salvo que la codicia extrema de uno de los grupos de poder forzara el sistema y condujera a un golpe o una guerra entre los mismos pactantes constitucionales. Y precisamente era eso lo que sucedía. La historia constitucional de innumerables países demuestra que con un sistema de representación corto y extremadamente a-representativo (censitario) no se evitaban innumerables golpes y guerras que a su vez generaban nuevos textos constitucionales para su legitimación ornamental. Por dos motivos:

- Enfrentamientos patrimonialistas entre facciones y partidos de la plutocracia en todos los grandes Estados europeos, de los que Francia ${ }^{8}$ y España ${ }^{9}$ serían exponentes, o en la práctica totalidad de nuevos Estados americanos, de los que pueden ser ejemplos los países conformados desde la plataforma político-territorial de la Gran Colombia ${ }^{10}$. En el Estado liberal más que de historia constitucional se podría hablar de codicia constitucional.

- La otra gran causa de inestabilidad y gobernabilidad sería la exclusión del sistema de representación sustancial de la inmensa parte de la ciudadanía, que solía ir acompañado de una desposesión material

\footnotetext{
${ }^{8}$ Francia es ejemplo europeo de constitucionalismo inestable, con doce constituciones hasta el definitivo termidor de 1875, una vez liquidado cualquier tipo de disidencia sustancial en 1871-2. Episodios continuados de permanente conflicto entre grupos de poder bajo sistemas de representación censales 0 de excepcionalismo extremo y permanente, donde se protagonizaron decenas de coup de force o de coup d'etat, que también dieron lugar a numerosas constituciones que abanderaban a distintos grupos de poder, ornamentados bien con sucesivas dinastías (borbones, orleanes, bonapartes) o repúblicas de facción. Resulta necesario recordar referencias bibliográficas críticas en este sentido (v. gr., González Casanova, 1984, "Teoría del Estado y Derecho Constitucional...").

${ }^{9}$ España sería el otro gran Estado europeo en el que grupos de poder cerrados y binarios -bajo la etiqueta de liberales o conservadores- protagonizan constantes golpes de estado y asonadas hasta llegar a la entente cordiale burguesa-nobiliaria en la $2^{\mathrm{a}}$ restauración borbónica, a causa del peligro que suponía la creciente reivindicación popular ("sexenio revolucionario") de espacios institucionales y sociales. Como en el caso anterior, se hace necesario el recordatorio de exposiciones complejas (v. gr., Clavero, 1984., "Evolución Histórica del Constitucionalismo...".

${ }_{10}$ Sirva de ejemplo toda la historia bélico-constitucional de Colombia, Ecuador, Panamá o Venezuela. Al estar sus Estados menos estructurados los enfrentamientos tomaron un cariz bélico extremo. En ningún momento la posibilidad de una mecánica representativa reducida y simple produjo estabilidad y consenso para la estructuración básica de esos nuevos Estados. Sólo cuando la presión popular se hace notable, y adviene el sufragio universal y derechos básicos de asociación las plutocracias son capaces de unirse en torno a un consenso de clase, bajo metodología de control caciquil y clientelista. Colombia sumó diez constituciones hasta 1886 y Venezuela otras diez constituciones hasta 1904 (Palacios, 2017, "La reformulación del Estado en la historia constitucional de Venezuela...", págs. 471-528).
} 
colectiva del común. Esta desposesión sustancial material originaría dialécticas que suelen nominarse como revolucionarias, y que sí lo podían ser en el sentido de desafección por falta de una simple representación en el hipotético nuevo marco constitucional de soberanía nacional ${ }^{11}$.

En definitiva, todo el convulso siglo XIX, con un sistema de representación reducida, no condujo a una mayor gobernabilidad y estabilidad. Más bien fue un conflicto permanente bajo dos dialécticas cruzadas: a) lucha oligárquica por el poder entre los 'tres estados'; b) lucha del cuarto estado por tener una presencia institucional ascendente.

B) Siglo XX: el sufragio universal en valor histórico relativo.

a) Primera fase de siglo: la distorsión democrática

Es necesario recordar que llegado el siglo XX el sufragio universal tampoco sería sinónimo de una representatividad notable, teniendo que atravesar el modelo constitucional representativo un recorrido histórico de distorsión (filibusterismo sistémico).

- Primera fase sufragista por la que fueron mediatizados y discriminados grandes sectores de la población, bien con legislación de exclusión (género, raza, ciudadanía), bien con normativas y técnicas electorales de manipulación (pucherazo, caciquismo, encasillado, gerrymandering), que evitaban una implantación básicamente representativa ${ }^{12}$.

- Cuando dichas técnicas no pudieron ser lo suficientemente eficaces para el control del movimiento ciudadano llegaría una mayor plural representación a los parlamentos, en torno al periodo de entreguerras. Se ha argumentado que, aún con todo -o precisamente por ello-, se generó ingobernabilidad cuando confluyeron sufragio universal y sistemas electorales menos intervenidos. Pero no, la falta de gobernabilidad no se produciría por el propio hecho del sufragio universal o por la implantación de técnicas más representativas sino porque el sistema político era ya

\footnotetext{
${ }^{11}$ Episodios gubernamentales o constitucionales como los de Francia $(1793,1845,1871)$ o los de España $(1868,1873,1931)$. Obsérvese que las causas de los cambios de régimen (inestabilidad) se suelen achacar a los "excesos democráticos" o a "sobredemandas populistas", y no a la presión, sabotaje, fuerza o violencia -política y social- ejercida por "actores reales y efectivos de poder" tanto en tiempo de pasado como de presente (Palacios, 1998 b, "Liberalismo y derechos virtuales...", pp. 15-64).

${ }^{12}$ Vid., Palacios, 2018, “Democracia, Representación y Sistema Electoral...", pp. 13-48.
} 
una máquina a presión con la débil espita de escape del acceso parlamentario que se desbordaría por la propia frustración social acumulada, los chantajes económico-financieros del poder fáctico y la correspondiente excepcionalidad para debilitar la institucionalidad de las nuevas fuerzas emergentes. En definitiva, la ingobernabilidad sería producida por un marco de debilidad constitucional económico-política ${ }^{13}$.

b) Segunda fase de siglo: la torsión democrático social

Desde finales de la II GM se combinaron distintas técnicas electorales en el grueso de países europeos que casi no aumentaron la representación respecto a los parlamentos más avanzados del periodo de entreguerras.

Dicha coyuntura no generó una crisis de representación por cinco motivos que añadieron notables pluses de legitimidad al sistema (plus social de legitimidad): 1) decayeron los modelos monárquicos de soberanía compartida que aún quedaban; 2) quedó mermada la influencia de los grupos de presión económico-financistas en la toma de decisiones institucionales; 3) por el contrario aumentaron otros actores sociales su papel activo (representativo) en la toma de decisiones del Estado, tal cual fueron las organizaciones de economía real (sindicales y patronales); 4) todo ello coadyuvó a la configuración de una renovación del contrato social que se plasmó en el Estado social bajo dos parámetros conexos: a) aumento sustancial y extenso en derechos sociales y económicos, y un consecuente crecimiento de la movilidad social ascendente, b) conformación de un sector público esencial y estratégico; 5) la nueva construcción de Estado (social) fue consensuada y dirigida bajo una "estructura institucional consensual", que tuvo como producto depurado las sinergias de coalición gubernamental entre las distintas fuerzas políticas. Estos cinco motivos se resumen en uno: institucionalización del modelo de Estado Social ${ }^{14}$.

De esa manera se aumentó la legitimidad del sistema constitucional a pesar de que el sistema político institucional parlamentario no se alimentaba de una

13 El ejemplo de manual fue Weimar (vid., Kühnl, 1991, "La República de Weimar: establecimiento, estructuras y destrucción..."). Teorías de referencia sobre la relación causaefecto del poder económico sobre el hecho político-constitucional en la gestación de la crisis político-económica de entreguerras, en Galbraith, J K., 2013, "El Crash de 1929..."; Kirchheimer, 1969, Politics, Law, and Social Change...".

${ }^{14}$ Palacios, 2016, "La lucha por la Constitución: una dialéctica entre Ágora...", pp. 1325 y ss. 
mayor proporcionalidad, y mucho menos se establecieron canales de participación ciudadana directa.

Esta inercia de legitimidad social consensuada generó tanto un abstencionismo parcial crónico como un ausentismo político derivado de una "ecuación de legitimidad suficiente" donde se contemplaban tres "sumandos": bienestar material, movilidad social ascendente y seguridad integral. Pero también, como en cualquier ecuación, existía una "incógnita" durmiente: la ausencia de una proporcional y activa representación política ("representación igual"), a la espera de un coadyuvante político negativo que le diera protagonismo.

c) Tercera fase de siglo: la involución democrático social

La teoría de la gobernabilidad tendría en la historia político-constitucional más actual dos momentos teórico-estratégicos:

- Un primer momento a principio de los años setenta para legitimar la deconstrucción de un sistema social (Estado social) que había alcanzado una sobresaliente estructura societaria de previsión social y una sobresaliente estructura estatal de control económico-financiero ${ }^{15}$.

La reformulación del Estado social a partir de la década de 1980 provocó la progresiva caída de los mencionados elementos de legitimidad del sistema, conforme fueron perdiendo fuerza (y reconfigurándose) determinados actores sociales (sindicatos, organizaciones pymes) y, por contra, aumentando su potencia (autónoma) actores de poder económico-financista. Y sin llegar a configurarse un mínimo de actores social-económicos en un proyecto de economía/derecho social que pudiera haber sido alternativo y equilibrador.

Ello confluiría en una menor capacidad de decisión por parte del Estado (pérdida de soberanía real) y, en definitiva, en un default progresivo del modelo social, con crecimiento de las tasas de desigualdad y merma de la movilidad social. Se iniciaba con ello una "crisis de legitimidad" del modelo ${ }^{16}$.

- La teoría de la gobernabilidad vuelve a irrumpir estratégicamente a finales del siglo XX para amparar la teoría y la práctica neoliberal a favor del gobierno hegemónico de mercado central de sesgo

\footnotetext{
${ }^{15}$ Actuación concertada, con hito de institucionalización para la nueva gobernabilidad, a partir del foro de la Comisión Trilateral en 1973 (Vid, nota 4).

${ }^{16}$ Palacios, 2016, pp. 1328 y ss. Cfr., De Cabo, 1986, "La crisis del Estado social..."; Porras, 1988, "Introducción a una teoría...".
} 
predominantemente financiero. Se ampara en el nuevo paradigma multinivel de nuevo orden mundial/globalización con referencia en tres instrumentos: a) histórico (caída del bloque soviético, 1991); b) teórico (fin de la historia/ideologías, 1992); c) técnico (consenso de Washington/ Financial Services Modernization Act, 1998-9). Dicho paradigma concluía en la necesaria (obligada) ordenación mundial bajo el criterio de una libertad con etiología dominante economicista, a la que se subordinarían todas las demás. El Estado se iría convirtiendo en una "entidad de sostenimiento gregario" para asistir a dicho movimiento de mercado central y, paralelamente, más desestructurado respecto a sus espacios de control para con dicha nueva economía ${ }^{17}$. De este paradigma multinivel se hicieron gregarias las posiciones de la mayor parte de fuerzas políticas $y$, en paralelo, las respectivas posiciones doctrinales jurídico-constitucionales. El mercado debía sustituir al Estado, y se asumía con mórbida naturalidad ${ }^{18}$.

La creciente devaluación de la representación institucional junto a la desvalorización de la economía real y la final aguda crisis financista de este periodo no es sorpresiva ni producida por una especie de "fuerza mayor apolítica" que sería el argumento de la clase política y de la clase financista. Existe una tendencia de los estamentos económico-políticos (y jurídicodoctrinales) a denominar "fuerza mayor" a las crisis económico financieras, desligándolas de sus actos propios, de su "prosapia ideológica de gobierno" (legislación, políticas públicas, sentencias, doctrina y, en definitiva, ideología). Una tendencia de inimputabilidad individual y grupal que intenta asimilar una crisis económico-financiera de naturaleza desreguladora a la etiología casual de un terremoto, una epidemia o una guerra ${ }^{19}$.

17 Las décadas 80-90 argumentan la gobernabilidad política a base de un a-gobierno económico. financiero, que termina en un radical desequilibrio entre las funciones de Estado y mercado (Stiglitz, 2003, Los felices 90. La semilla de la destrucción...”).

${ }_{18}$ Joaquín Estefanía recogía la afirmación de George Soros justo a finales del siglo XX ("Los mercados votan cada día, obligan a los gobiernos a adoptar medidas ciertamente impopulares, pero imprescindibles. Son los mercados los que tiene sentido de Estado"). Y recordaba como este diktat del especulador más connotado era extensión de una línea de filosofía política desde "la fábula de las abejas" de Mandeville, justo ahora dominante en el cambio de siglo (Estefanía, 2000, "El poder en el mundo...", pp. 48-51).

${ }^{19}$ No es baladí desde una perspectiva de constitucionalismo económico una reflexión completa de Luis Ángel Rojo (gobernador del Banco de España 1992-2000), que había estado avalando políticas públicas y normativas desreguladoras y privatizadoras: "los mercados tienen capacidad para condicionar y modificar políticas nacionales, imponer ajustes cambiarios e incluso hacer saltar sistemas de cambios fijos, acentuar la volatilidad de los precios de los activos financieros, zarandear las economías generando desequilibrios que pueden acabar 
La pérdida de legitimidad política en una primera fase (1983-2000) no viene tanto por una crítica a la directa falta de participación y representación igual sino por la percepción civil-popular de una caída drástica del aprovisionamiento social. Una primera fase protestada con huelgas y movilizaciones de las generaciones mayores, que fueron apagadas con políticas públicas asistencialistas y clientelistas estructurales sobre la presión del sistema de seguridad social y de la estabilidad presupuestaria de los Estados, a lo que habría que añadir la sobrevenida promesa taumatúrgica de una estructura unión-europeísta.

La reacción de una parte de la sociedad civil-popular sería una reacción o protesta de coyuntura, medida, bajo una sensación de desconcierto que llevó a cierta parálisis; otra parte de la sociedad civil se manejaría entre el desconcierto y cierta asimilación del estado de cosas propuesto. El siglo termina con una desafección creciente en convicción y lealtad institucional ciudadana ${ }^{20}$.

Finalizado el siglo XX las nuevas generaciones sociales se encontrarían con una merma de las prestaciones (derechos) sociales progresivamente más acusada, reconvertidas en prestaciones asistencialistas de coyuntura, un Estado en progresivo default, con una crisis de identidad como modelo respecto a un contra-modelo soberano como supone el sistema de globalización. Por otro lado, una sub representación de la disidencia, sin canales para ejercerla, en paralelo a una ausencia de los principios de transparencia, junto a la ineficacia de los mecanismos de control operados desde una clase política que comienza a ser cuestionada bajo un estatuto de casta $^{21}$.

conduciendo a inflaciones o recesiones, y difundir las tensiones de unos mercados a otros aumentando la probabilidad de que se generen riesgos sistémicos (...) Ha habido un desplazamiento de poder desde los gobiernos a los mercados, cuya consecuencia es una pérdida de autonomía de las autoridades nacionales en la elaboración de la política económica" (Estefanía, 2000, El poder..., pp. 49-50).

${ }^{20}$ La sensación y reacción de la ciudadanía es una combinación de: a) la propuesta de Klein (2007, "La doctrina del shock..."), en cuanto al conjunto de acontecimientos sistémicos confusos por un lado y paralizantes por otro, analizados en percepción apocalíptica, con la intención de producir desconcierto, parálisis social, y coadyuvados por medidas excepcionales de seguridad (v. gr., 11-S, y el sucesivo combo normativo de medidas de "ordinaria excepcionalidad", como la USA Patriot Act, o la británica Antiterrorism, Crime and Security Act ); b) la percepción de cómo las formas y políticas públicas de gobierno, así como sus correspondientes afectaciones sociales negativas estaban entrando en una inestabilidad creciente (Judt, 2010, Algo va mal...").

${ }_{21}$ Palacios, 2016, "La lucha por la Constitución...", 1330 y ss. 


\section{La crisis del Estado en el cambio de siglo: ingobernabilidad financista, subordinación institucional y reacción civil-popular}

Las coyunturas de crisis de finales del siglo XX no fueron pasajeras como matizaban los partidarios de la nueva economía y de la nueva política. Quedaba la crisis de 2008 que no sólo patentizaba el desequilibrio entre Estado y mercado, sino también el desequilibrio radical del propio mercado produciendo una "sistémica ingobernabilidad", producto del trasvase de poder Estado-mercado y del apoderamiento de los mecanismos de funcionamiento del sistema por parte de puros poderes fácticos. Un Estado que perdía poder, y que denotaba una mezcla entre complicidad y falta de capacidad operativa ante el nuevo statu quo financista ${ }^{22}$.

En esta fase (1995-2020) la reacción de la ciudadanía ya no sólo es una reacción o protesta de coyuntura, medida, bajo una sensación de desconcierto que llevaba a cierta parálisis, sino que es una reacción más integral y proactiva. La pérdida de legitimidad política es ya no sólo en cuanto a frustraciones económico sociales que se habían hecho ver como inevitables y pasajeras, sino también de vindicación política, siendo ya un planteamiento de "crisis de legitimidad política aguda", que se canaliza en una dinámica de extremosidad crítica ciudadana en la que se exige una catarsis de sistema. Hay una impugnación del sistema que se concreta en la crítica general: a) pérdida de bienestar social, b) corrupción/ineficacia institucional. Esta masa crítica es amorfa en principio, vindicativa del malestar de una mayoría social popular muy transversal socio culturalmente. No obstante, sí hay espacios ciudadanos que se manifestarían de manera más explícita, y que representan a la masa crítica social general en la parte de crítica negativa del estado de cosas ${ }^{23}$.

En conclusión, un grueso importante de la ciudadanía percibe cómo el núcleo de las recurrentes crisis económico-sociales no es un fenómeno coyuntural o cíclico fatídico, sino que tiene su etiología en un decrecimiento de la ya precaria

\footnotetext{
${ }^{22}$ De Vega, 1998, "Mundialización y Derecho constitucional ...".

${ }^{23}$ En una situación de crisis el malestar general nunca es sinónimo de malestar igual. Siempre hay causas comunes, pero también causas muy dispares; y eso ha sido una constante en todos los conflictos modernos ya sean de baja o media intensidad, o bien revoluciones agudas. De manera idéntica ocurre con la movilización político-social masiva, que es síntoma de malestar agudo general, pero que no se corresponde en sus actores inmediatos con todas las sensibilidades sociales críticas (v. gr., clásicos del conflicto tan antagonistas como Coser, 1970, "Nuevos aportes a la teoría del conflicto..."; Brinton, 1962, "Anatomía de la Revolución..."; Sorel, 1976, Reflexiones sobre la violencia...".
} 
representación, en el proceso de sustitución y avocación fáctica institucional en la representación de una ciudadanía, por parte de una partidocracia notablemente condicionada por los intereses grupales de agentes económicos con hegemonía sistémica. Esta horadada institucionalidad resiste precariamente por: a) el sustento clientelista a grupos sociales (vulnerables, en movilidad social descendente), asistidos por una administración pública neo gestora, b) el temor de las clases medias a perder más posición de subsistencia por agravación de las crisis. Podría decirse que la crisis de Estado social conlleva una crisis de Estado general.

Sobre aviso de la misma había economistas, filósofos, juristas o comunicadores. Los había desde la década de los noventa, pero también desde el comienzo de la mutación del modelo de Estado a partir de finales de los años sesenta, ya desde la fase amable del Estado social, cuando no existía crisis de legitimidad general; así se manifestarían críticamente clásicos teóricos del Estado advirtiendo sobre déficits democráticos ${ }^{24}$, e incluso sobre la apertura de canales de deconstrucción del Estado social ${ }^{25}$.

Desde principios del siglo XX también se irían sumado a la necesidad de un renovado binomio participación-representación antiguos teóricos de la representación modulada ${ }^{26}$. Cuando el último redactor vivo de la Declaración Universal de Derechos de 1948, Stéphane Hessel, exclamó "indignaos" en 2010 se culminaban varios decenios de continuadas advertencias teóricas sobre una suma de agravios depositados sobre la ciudadanía ${ }^{27}$.

La crisis de legitimación se manifestó bajo el supuesto previo de "contrapoder", no como estructura sino como una amplia actitud de rechazo básicamente volitiva y espontánea. Entendiendo por ello un trasunto más complejo que las simples manifestaciones, y que comprende no sólo la expresión visual y directa callejera sino una vis crítica social relevante que se activa en otros muchos espacios con una percepción de base como contrapoder volitivo (no organizado y muy parcialmente visibilizado $)^{28}$. Puede abarcar un espectro de sensibilidades

\footnotetext{
${ }^{24}$ V. gr., Habermas (Historia y crítica de la Opinión Pública, 1962), Duverger (La democracia sin el pueblo, 1967), Ferrajoli (Democracia autoritaria y capitalismo duro, 1978).

${ }^{25}$ De Cabo, 1986, "La crisis del Estado social...".

${ }^{26}$ V. gr., Pitkin (Representación y Democracia, 2004); Urbinati (Democratizando la deliberación, 2006). Especialmente el caso de Pierre Rosanvallon (2006), La contré-démocratie. La politique á l'age de la défiance, Un análisis al respecto en Palacios, 2018, "Democracia, representación y sistema...", pp. 22 y ss.

27 indignaos! Un alegato contra la indiferencia y a favor de la insurrección pacífica (2010).

${ }^{28}$ Cfr., Perrieneau, 2003, "Le Désenchantement démocratique...".
} 
muy confuso y cambiante ideológicamente, como así lleva ocurriendo en la crisis de legitimidad de siglo XXI. La "movilización ciudadana crítica" será un fenómeno focalizado, pero paralelo a una mucho más general percepción social volitiva de la necesidad de contrapoder no explícitamente movilizada. La movilización ciudadana se habrá dividido en tres fases.

\section{A) Espontaneísmo cívico-popular crítico: la denuncia del apoderamiento financista globalizador como defensa del icono soberanía}

En una primera década (1995-2005) la movilización crítica se manifiesta en varias modalidades sucesivas visibles: a) virulencia general sobre los efectos de la globalización en todos los presupuestos del concepto soberanía, tanto nacional como popular; b) virulencia estratégica a modo de protesta aguda a tótems e instituciones emblemáticas económico-mercantiles del statu quo; c) cívica-intelectual, con base en una consistente crítica temática -sustancialmente económico social- aunque sin planteamiento estratégico. Cada una de estas movilizaciones explícitas de protesta contiene una espontánea retaguardia informal (no visible), con otros sujetos sociales que sin manifestarse ni alinearse formalmente avalan volitivamente la protesta y, sobre todo, la crítica al estado de cosas. La forma crítica más visibilizada fue la irrupción de los movimientos antiglobalización, bajo formas organizativas atípicas y espontaneas, al margen de los partidos establecidos incluidas las formaciones políticas clásicas de corte rupturista ${ }^{29}$. También irrumpieron organizaciones de espectros ideológicos contrarios -de referente ideológico popular nacionalista- que asumieron también la reivindicación de la crisis de legitimación soberana y social de manera menos manifiesta, pero con igual contundencia y progresiva influencia psicológico-social ${ }^{30}$.

\footnotetext{
${ }^{29}$ Cfr., Pastor, 2002, "Qué son los movimientos antiglobalización...”; Taibo, 2005, “Movimientos de resistencia frente a la globalización...". No obstante, los movimientos antiglobalización tienen su origen ya desde finales del siglo XX (Primer Encuentro Internacional por la Humanidad y contra el Neoliberalismo, México, 1996), precedido de movilizaciones internacionales contra el TLCAN y el 50 aniversario del FMI (1994). La contra cumbre de Seattle (1999) -abortando la cumbre de la OMC- posee apuntes estratégicos que se visualizan en nuevas formas de organización binaria (network-streetwork, caso de Direct Action Network). Posteriormente hubo una sucesión de notables protestas binarias (v. gr., Contra cumbre G-8, Génova 2001).

${ }^{30}$ Con un origen ascendente desde finales del s. XX (Perrineau, 2000, "Les Croisés de la société fermée: les extrêmes droites..."). Mención aparte requiere el Frente Nacional en Francia por ser pionero en reconfigurar institucionalmente (constitucionalmente) la ideología conservadora extra sistema, con un nuevo y potente enfoque institucional, social y transversal 
El movimiento de progresiva disidencia antiglobalización fue cortocircuitado temporalmente por la vis expansiva político-judicial que generaría una base normativa de excepcionalidad (ordinaria excepcionalidad), a partir del 11-S, con constructos normativos marco -USA Patriot Act (2001) ${ }^{31}$, Anti-terrorism, Crime and Security Act $(2001)^{32}$, Decisión de la Unión Europea (2002) ${ }^{33}$ - a modo de despliegues de excepcionalidad utilizados como instrumentos gubernativos de ordinaria excepcionalidad (erga omnes, omnem terram) y que seguirán siendo modulados de manera indefinida ${ }^{34}$. Por otro lado, se genera una "cultura gubernativa de la excepcionalidad" a través de una intensa red opaca para el acopio de información cuyo uno de sus objetivos es conformar un listado político-social de estructuras de divergencia con el objeto de su anulación o debilitamiento ${ }^{35}$.

B) Movilización incardinada, alternativa y constitucionalismo crítico: crítica de la representación y reivindicación de acceso igual institucional

Una segunda década (2006-2015) con una movilización cívica con canales comunicacionales progresivamente más estratégicos (movilización incardinada) pero que adolecerían también de niveles altos de espontaneidad y, por lo tanto, de carencias tácticas y estratégicas suficientes. El reactivo más visible serían las movilizaciones generales de $2011^{36}$. Escenifican una enmienda al sistema de representación ("no nos representan"), que se puede hacer especialmente visible merced a la posibilidad de nuevas formas de participación escénica como la configuración espontánea a través del sistema de red ${ }^{37}$. Bajo un pool

(v. gr., clásico y clarividente análisis en Mayer \& Perrineau, 1989, "Le Front National a decouvert...").

${ }^{31}$ United States Congress, 2001, "USA Patriot Act...".

32 Ley ómnibus en el Reino Unido a rebufo de Estados Unidos, anticipándose a la decisiónmarco europea (Parliament of the United Kingdom, 2001, "Crime and Security Act...").

${ }^{33}$ Consejo de la Unión Europea, 2002, "Decisión marco sobre la lucha...", por la que se instaba a los Estado miembros a regular en todos los ámbitos jurídicos normativas antiterroristas. Su vis expansiva ha acabado siendo utilizada para el recorte selectivo del ejercicio de derechos y libertades.

${ }^{34}$ Lo que se ha venido en Ilamar criminalización jurídica de la protesta (v. gr., Ley Orgánica 4/2015, de 30 de marzo, de protección de la seguridad ciudadana).

${ }^{35}$ V. gr., toda la teoría sobre los sistemas de construcción colaborativa inter-estatal (Mass surveillance y Global surveillance); un archivo bibliográfico exhaustivo en Universidad de Oslo (UiO, "Global surveillance...").

${ }^{36}$ Cfr., una exposición general sobre causas, naturaleza y composición, en Monge, 2017, "15M. Un movimiento político para democratizar...".

${ }^{37}$ Superando los límites clásicos impuestos para la disidencia por el tradicional cierre parcial del espacio mediático y del espacio institucional (vid., Castells, 2012, Redes de indignación y esperanza. Los movimientos sociales..."). 
sociológico político con base en: a) estado crítico de opinión general, de percepción crítica inter-generacional, inter-ideológica e inter-política y, en menor medida, inter-clasista; b) dos temáticas centrales: temática económicosocial, y la relativa al modelo de representación, gestión y control del poder institucional (transparencia, corrupción, información, comunicación, técnica electoral, auditoría ciudadanía). Todo ello dotado de un discurso-base muy transversal socioculturalmente hablando ${ }^{38}$.

Su discurso es heredero del elenco temático contrario al neoliberalismo y al trasvase de poder desde el ágora (ciudadanía) al fórum (grupos de poder financiero), pero con una diferencia con la movilización antiglobalización: se focalizan problemas en espacios próximos, se adquieren improntas de generación movilizadora locales, abordan temáticas de orden nacional, analizan decursos institucionales de Estado y, en suma, plantearán problemas de legitimación sujetos a la problemática nacional respectiva, y entre los que destacan los problemas de representación. El problema de representación será el progresivo trasvase operado en las últimas décadas desde el poder soberano institucional (parlamento, gobiernos, instituciones de control) hacia los poderes fácticos, que habrían realizado una progresiva captura de toda la compleja arquitectura orgánico-administrativa para 'regular la desregulación', desde parámetros organizativos globalizadores (organismos económico comerciales de Naciones Unidas, y la propia arquitectura de la Unión Europea). La mayor parte de los contenidos de la propuesta no se hacen bajo ningún supuesto de proceso constituyente de ruptura de sistema (revolucionario), sino de propuestas perfectamente asumibles en cualquier debate constitucional, de reforma constitucional o de proceso constituyente homologable respecto al modelo Estado social. Desde esta perspectiva ("constitucionalismo crítico") se

\footnotetext{
${ }^{38}$ V. gr., desde el 15-M en España a Occupy Wall Street en Estados Unidos, bajo su clásico aserto de: "la única cosa que todos tenemos en común es que somos el $99 \%$ de los que no tolerará más la codicia y la corrupción del 1\%" (Gitlin, 2012, "Occupy Nation: The Roots, the Spirit..."). También en este sentido el documento omnicomprensivo y transversal de la organización fundacional Democracia Real Ya, 2011, "Manifiesto..."; así como interpretaciones personales de actores directos (Taibo, 2011, "Nada será como antes. Sobre el movimiento..."; Monedero, 2011, Dormíamos y despertamos. El 15-M...". Cosa diferente es cómo dichos movimientos, desde el 2012 a 2015, pudieron ir perdiendo transversalidad y capacidad de sinergia respecto a una masa social crítica más amplia que los fortaleciera; fundamentalmente al ser afectados por espacios de reivindicación sectorial egotista, con dificultad para lograr una transversalidad que sí suscitaban en origen las dos temáticas primigenias ya mencionadas (económico-social y representación-control).
} 
venía a decir que 'antisistema' no era el movimiento de protesta, sino los actores de la progresiva banalización constitucional ${ }^{39}$.

C) La apuesta institucional-constitucional: entre la defensa holista del modelo de Estado (social) y el diletantismo de los espacios diversos

El anterior impulso movilizador 2000-2015 da lugar a la irrupción de nuevos movimientos/partidos políticos alternativos que, a pesar del cerrojo del sistema electoral e institucional, consiguen acceder a las instituciones, con un planteamiento tentativo transversal de "cultura política alternativa holista" extensa y sustancial. El lustro 2015-2020 conlleva una mayor formalización estratégica organizativa de lo planteado anteriormente, y un final acceso electoral-institucional ("movilización estratégica institucional”).

Partidos alternativos con un programa no antisistema, sino de reivindicación constitucional sustancial igualitaria ("cultura política alternativa holista") con dos líneas:

- Una primera nada novedosa, ya que reivindica los contenidos sustantivos del propio Estado social; con programas económico sociales semejantes o incluso más moderados que las políticas públicas institucionales de la Europa de postguerra: desde el control de servicios estratégicos al programa de vivienda, pasando por servicios públicos esenciales (sanidad, educación), sistema de previsión o sistema financiero. Todo ello bajo lógica de la soberanía perdida.

- Una segunda de profundización democrática con apelación a una mayor presencia y eficacia de los mecanismos de toma de decisiones directas ("participación directa"); así como una catarsis del sistema de representación a través de sistemas electorales más proporcionales (parlamentos, asambleas institucionales), canalización técnica de discursos más plurales y refuerzo de mecanismos de control y transparencia; en síntesis propuestas que hablan de una depuración

\footnotetext{
${ }^{39}$ Vid., Subirats, 2011, "Otra sociedad, ¿otra política?”. En este mismo sentido, apuntando a la insuficiencia constitucional: Ferrajoli, 2011, "Poderes salvajes. La crisis de la democracia constitucional...". Una cita personal en cuanto a discusión de contenidos en los foros del 15-M (Huesca y Zaragoza): Palacios \& 15-M Huesca, 2011, "Mecanismos de control, transparencia y pluralismo..." y "Antisistema son ellos: Bases constitucionales..."; de manera más desarrollada: Palacios, 2014, “Del proceso destituyente al debate constituyente...", pp. 237-331.
} 
técnica y enriquecimiento deliberativo de los canales para el acceso institucional ("representación") ${ }^{40}$.

Cuestión diferente sería el debate sobre la irregular capacidad operativa de los nuevos partidos alternativos para conseguir una "consolidación institucional eficaz"; por dos causas, una de tipo endógeno y otra de casuística exógena:

- La causa endógena atañe a la incapacidad de lograr mayor transversalidad socio cultural y capacidad de sinergia política respecto a una "masa social crítica suficiente" que los fortaleciera. Cuestión que tendría que ver con mermar la centralidad de discurso, programa y estrategia respecto a la mencionada "cultura política alternativa" (holista) con sustancialidad del factor económico social y del factor participativo representativo- como planteamiento de incidencia sistémica y estructural. $Y$ por el contrario adoptar como sustancialidades espacios de reivindicación sectorial-individual con bajo índice de cohesión y de percepción ciudadana suficiente o positiva, que generará un programa político de diversionismo ideológico (diletante) en torno a temáticas notables, pero no sustanciales ${ }^{41}$.

- Una segunda casuística endógena es la relativa a la "ineficacia/impotencia operacional" (insuficiencia/carencia) de cuadros que se produce cuando se da una baja voluntad o capacidad para el reclutamiento de elites capaces, experimentadas, eficaces y ubicadas respecto a la extraordinaria y hostil complejidad de una coyuntura de gobierno; coyuntura dominada por una clásica institucionalidad hegemónica, una administración pública establecida o gregaria y unos poderes fácticos hostiles a políticas de renovación y catarsis. Elites

\footnotetext{
${ }^{40}$ Sirva de ejemplo cualquiera de los programas políticos de las formaciones europeas alternativas más relevantes en torno a estructura económico-social y político-representativa, y salvando sus acusadas diferencias en temas sectoriales y priorización temática (Podemos, Syriza, La France insoumise, Movimento 5 Stelle, Die Linke). Y en la misma línea cualquiera de las propuestas en foros colaterales a dichos partidos (v. gr., las propuestas de la "Instituto 25-M Democracia" en cuanto a reforma constitucional, en la obra colectiva sobre Proceso constituyente y cambio constitucional para la España del siglo XXI (Monereo, 2018)).

${ }^{41} \mathrm{La}$ antítesis de un planteamiento sistémico (holista), donde se da prioridad a cuestiones estructurales, será un planteamiento fragmentado sin priorizaciones claras (diletante), un "diversionismo foquista", sectorial, de temas notables, pero que su potencial deriva egotista pone en riesgo el mencionado planteamiento alternativo holista, a través de la priorización programática de una sectorialización fragmentaria (medio ambientalismo, género, memorialismo, asistencialismo, animalismo...). Es esta una cuestión ideológica y estratégica básica en todo el desarrollo del espacio crítico al que nos estamos refiriendo; de compleja o errada interpretación desde los anaqueles teóricos de la escuela de Frankfurt (para una perspectiva similar, cfr. Bernabé, 2018, "La trampa de la diversidad...").
} 
articuladas alternativas imprescindibles para afrontar la siguiente casuística exógena.

La casuística exógena apela a la falta de "capacidad alternativa real", eficaz (factual) de gobierno, con posibilidad para gestar políticas públicas alternativas. Siendo esto último complejo y debido a las sujeciones económicas y opacas imbricaciones burocrático normativas del actual statu quo (sistema), instalado en un (¿paradójico?) sistema de neoliberalismo determinista, tecno-burocratizado y asistencialista ${ }^{42}$.

El fracaso en trabajar sinergias, transversalidad y de poder operar con eficacia contra el statu quo podría dar (y estaría dando) protagonismo a desafecciones sociales que se inscriben en corrientes del popular-nacionalismo anteriormente comentado, canalizadas en partidos ad hoc que se visibilizarían de manera mucho mayor que a finales de siglo $\mathrm{XX}^{43}$.

Toda esta parte primera ha intentado evidenciar como las mecánicas políticas restrictivas de la representación, la participación y el principio de control son susceptibles de mermar los presupuestos constitucionales de soberanía, de equilibrio socioeconómico y de igualdad, habiendo propiciado a comienzos de siglo XXI la deconstrucción del Estado social, y podría decirse que del propio Estado en gran medida. Por todo ello una de las labores necesarias para rescatar un modelo de Estado (social-democrático) en default sea la institucionalización integral de la disidencia, del debate alternativo, del intercambio de ideas y, más en concreto, de la reflexión común sobre el statu quo político-constitucional y un posible compromiso de interés dentro de las instituciones. Presupuestos sólo asequibles a través de la generación de una democracia representativa pura con canales para el gobierno institucional.

\footnotetext{
42 No tan paradójico. Como ocurría al principio de este capítulo con la "concepción gobernabilidad", que nos remitía en su versión clásica a su descripción en la Grecia de Jenofonte, algo semejante ocurre con la 'sistemática técnico-burocrática neoliberal', que no deja de ser una versión avanzada del constructo de la "jaula de hierro" de Max Weber. En este sentido episodios como el gobierno Syriza (Grecia 2015-2019), o, salvando las muchas circunstancias accidentales cualquiera de los modelos del nuevo constitucionalismo latinoamericano (Ecuador, Bolivia, Venezuela).

${ }^{43}$ Partidos de rápido crecimiento en el último lustro: AFD (Alemania), FPO (Austria), VB (Bélgica), VOX (España), PS (Finlandia), EKRE (Estonia), RN (Francia) y varios otros. Susceptibles de agruparse en perfiles ideológicos muy diferentes, desde el nacionalismo/comunitarismo social al autoritarismo neoliberal.
} 
III. DEMOCRACIA REPRESENTATIVA PURA Y CANALES PARA EL GOBIERNO INSTITUCIONAL

Como dicta el enunciado de esta parte, aquí sólo se va a reivindicar la representación popular pura y exacta, dejando al margen el resto de problemas notables del sistema de representación ${ }^{44}$. Y consiguientemente se van a enunciar una serie de premisas que reflejen la posibilidad de conseguir gobiernos institucionales estables y eficaces sin necesidad de mermar la mencionada representación pura.

Lo aquí propuesto no sería una solución para desarrollar y cerrar un nuevo modelo de Estado que acabe con la crisis de ingobernabilidad radical sistémica expuesta en la primera parte de este trabajo, ya que dicha crisis al ser sistémica afecta a la base de configuración económico-social sustancial. Pero aquí se mantiene, como hipótesis, que cuando menos se podrán lograr dos objetivos: a) generaría cauces para la representación de todos los movimientos con repercusión social y habilitaría mecanismos de concertación, consenso y cogobierno; b) como consecuencia de lo anterior, la presión social tendría cauces mayores de institucionalización y la necesidad de concertación y consenso posibilitaría que entrara en el Estado un flujo más diverso de ideas y capacidad institucional (constitucional) de contra-facticidad ("contrapoder institucional"). Como última cuestión cabría la necesidad de que para coyunturas sin suficiente capacidad de consenso hubiera que habilitar mecanismos de parlamentarismo negativo. Una servidumbre de último recurso planteada sobre la base de primar el principio democrático, al intervenir la corrección de la proporcionalidad en espacio parlamentario ("corrección representacional" ex post) que no hacer una corrección de la proporcionalidad en el espacio electoral ("corrección representacional" ex ante).

\section{Democracia representativa pura}

A) Breve alusión a la ya consabida técnica de desproporcionalidad electoral. La discriminación ideológica 'ex post' acto

\footnotetext{
44 Problemas tales como: a) cultura electoral cívica discriminatoria; b) financiación desequilibrada; c) sistema insuficiente de inelegibilidad, incompatibilidad y estatuto del representante; d) burocratización excluyente; e) normativa electoral fluctuante; f) e-democracia inédita. Un desarrollo de dichas problemáticas en Palacios, 2018, "Democracia, Representación y Sistema Electoral...", pp. 13-48.
} 
Lo que aquí se va a decir es de sobra sabido: el coste de los escaños para los diferentes partidos políticos es muy diferente en las técnicas electorales no proporcionalmente puras. Algo que se ha normalizado, apoyado e incluso impuesto como dogma funcional. Sin embargo, es la ruptura flagrante del que pasa por ser el primer axioma democrático: "un hombre un voto"45. Axioma de base del principio democrático que sirvió para eliminar la discriminación del derecho universal con base a raza, género y clase, pero no así a ideologías o posiciones políticas que se ven discriminadas ex post acto en el disfrute de tan incontestable axioma. Dicha discriminación genera una ruptura del principio universal en su cuantificación con causas sistémicas y consecuencias políticas nada asépticas.

En una anterior publicación dejaba apuntados varios parámetros respecto a la desproporción:

a) La cuantificación matemática: entre la desvalorización y la lapidación de alternativas políticas

Se han elaborado decenas de índices sobre cómo afecta la simple introducción de una fórmula matemática al principio de la igualdad representativa. Hasta 19 índices hay para ello ${ }^{46}$. Cada uno de ellos denota como los resultados de los partidos quedan a merced del legislador interesado política e ideológicamente en dichas resultas, y, a su vez, como poder corregir perfectamente dicha desproporción.

El sistema electoral es un juego entre vectores tales como circunscripción (tamaño), territorio (prima), merito suficiente (barrera), grosor institucional (escaños) y, sobre todo, conjuro matemático (técnica), que conforman una "ecuación electoral diferencial", a partir de la cual poder facturar un sistema de partidos y de representación funcionales a los intereses del statu quo correspondiente. Tal juego da lugar a consecuencias políticas numéricas rocambolescas, que son mucho mayores en las técnicas mayoritarias, en donde partidos de representatividad notable son literalmente barridos en su representatividad.

\footnotetext{
${ }^{45}$ Desde que no hay igualdad de derecho al sufragio se esgrime la frase de una u otra manera, hasta el punto de ser una de las pocas expresiones complejas que tiene entrada propia en Wikipedia.

${ }^{46}$ A título de ejemplo, índices de proporcionalidad (Saint-Lagüe, Lijphart, Cox, Shugart...) o de desproporcionalidad (Rose, Rae, Loosemore/Hanby, Gallagher...). En este sentido un estudio exhaustivo en Soriano, 2018, "El sistema electoral del Congreso de los diputados...", pp. 73128.
} 
- Técnica mayoritaria (o la regla que prescinde de la mitad de la ciudadanía)

Practicado por las llamadas democracias más antiguas (Reino Unido, Estados Unidos y Francia), las cuales albergan un sistema crónico de duopolio de partido.

Un primer ejemplo reciente serían las últimas elecciones generales en Francia (2017) a la Asamblea Nacional (mayoritario de balotaje), donde la desproporcionalidad situaría el valor de un voto en 18 veces menor de valor que el voto del partido más votado. Con lo que llegaríamos a la conclusión de cómo el valor contable político de un voto/ciudadano alfa puede ser 18 veces mayor 07 veces mayor que el de un ciudadano de otros partidos muy representativos, cuya sinonimia contextual lo situaría bajo estatus de ciudadano "omega" o "sigma"47. Otra paradoja democrática notable es como un partido con muchos menos votos que otro obtenga hasta un $500 \%$ más de escaños que el partido con más votos ${ }^{48}$. Siendo el caso más extremo cuando el valor de 1 voto es 46.5 veces inferior al valor de 1 voto del partido ganador ${ }^{49}$. Estaríamos ante una técnica mayoritaria a dos vueltas en circunscripciones uninominales, que obliga al ciudadano a la renuncia o desnaturalización de su opción natural y, en cualquier caso, a que el voto primario natural de millones de electores sea devaluado ad nauseam, incluso hasta el punto de que el ganador se convierta en el perdedor ${ }^{50}$.

Un segundo ejemplo reciente serían las elecciones generales en España (2019) al Senado (mayoritario nominal, restringido o limitado). La técnica mayoritaria limitada llevó a que un partido con más de 7.7 millones de votos (nominales) y un partido con 4.9 millones de votos (nominales) quedaran sin

\footnotetext{
47 Dato extraíble de las elecciones generales en Francia a la Asamblea Nacional (2017), considerando los votos obtenidos en primera vuelta por los dos siguientes partidos ideológicamente más representativos. El voto de un ciudadano simpatizante de Rassemblement national sólo valió para conseguir 8 escaños con un coste de 373 . 826 votos por escaño, con lo que el coste de cada escaño fue 18 veces superior al del partido ganador $L a$ République en marche, que conseguiría 350 escaños a un coste de 20.923. Esta desproporción la sufriría también La France insoumise con un coste electoral 7 veces superior, de 146.921 votos por escaño (Ministère de L'interiéur, 2017).

${ }^{48}$ El caso del Parti socialiste respecto a Rassemblement national y La France insoumise, que conseguiría una representación de más de un $500 \%$ y $250 \%$ respectivamente respecto a ambos partidos (Ministère de L'interiéur, 2017).

${ }_{49}$ El caso de Europe Écologie Les Verts que con 973.739 votos sólo obtuvieron 1 escaño de 577 (Ministère de L'interiéur, 2017).

${ }_{50}$ Un ejemplo clásico al respecto fueron los resultados de las elecciones generales de 1958, donde el Partido comunista francés obtuvo 10 escaños con 3.882 .204 votos (18.90\%) y la Unión por la nueva república obtuvo 189 escaños con 3.603 .958 (17.60\%).
} 
representación (electa). Estamos ante un sistema que deja con representación "0" a partidos con peso social y político notable que incluso llegan a formar parte del gobierno de coalición ${ }^{51}$. Los dos partidos más votados (Partido Socialista y Partido Popular), con un porcentaje de voto del 58\%, consiguen un $85 \%$ de representación; resultado que no es más abrumador por la existencia de partidos territorializados, ya que en caso contrario el porcentaje obtenido extrapolado de los dos partidos mayoritarios podría haber sido del $99 \%$ de los escaños ${ }^{52}$.

\section{- Técnica proporcional "corregida"}

Hasta donde alcanza el diccionario por el que nos regimos 'proporción-alidad' significa "Disposición, conformidad o correspondencia debida de las partes de una cosa con el todo". 'Proporcional corregida' no deja de ser un oxímoron.

Técnica que de igual manera se podría denominar "mayoritaria corregida" en múltiples de sus variantes (cociente/cuotas, o incluso modelos de divisor como D'Hondt o Imperiali) ya que se sigue primando generalmente a los dos grandes partidos en general y, sobremanera, cuando se conjugan otros elementos reduccionistas -como en el caso de España- ingeniados en torno al territorio: circunscripciones reducidas, número de escaños elegibles reducido y barrera electoral reducida. $Y$ donde, sobre todo, se puede incrementar el reduccionismo territorial primando dicho reduccionismo con escaños ad hoc ${ }^{53}$.

La que podemos llamar "proporcionalidad española" está inscrita dentro del campo del sistema mayoritario, según alguna de las escalas de medición clásicas más relevantes. La prueba de la sobrerrepresentación podrían ser todas las elecciones realizadas en España hasta las elecciones generales de $2015^{54}$, en donde -después de 37 años de régimen constitucional- dos partidos consiguen romper parte de las barreras técnicas impuestas.

Las elecciones de 2008 son las que mejor pueden reflejar los efectos perversos desproporcionados de la técnica, puesto que dos partidos emergentes, ya sea

\footnotetext{
${ }^{51}$ Los casos de Unidas Podemos: 7.792 .400 (12,46\%) y de Ciudadanos: 4.900 .810 (7,83\%) que quedarían sin ninguna representación electa.

${ }_{52}$ Sólo un partido de implantación nacional -Vox, con 2 escaños- superó el exterminio de su representación.

${ }_{53}$ Las implicaciones de la falta gruesa de proporcionalidad de determinadas técnicas denominadas proporcionales -esencialmente la española- es un elemento clásico conocido en el que no es necesario insistir (vid., Liphart,1994, Sistemas electorales y sistemas...).

${ }^{54}$ V. gr., Lijphardt, 1985, "The field of electoral systems rearch..." (cit., en Valles, 1986, Sistema electoral...), p. 12
} 
de más anterior data (Izquierda Unida) o de creación reciente (UPyD), tuvieron un coste por escaño de un $600 \%$ y de un $500 \%$ respectivamente, en comparación con el coste del escaño del PSOE, o casi en la misma proporción del PP. Tesitura que puso a IU en el borde extraparlamentario y dejó a UPyD en vías de segura extinción.

Podría alegarse que desde 2015 el sistema permite la irrupción de nuevos partidos, puesto que ha habido entradas significativas (Unidas Podemos, Ciudadanos, Vox, incluso Más País). Sin embargo, el mapa de las elecciones generales de 2019 (noviembre) denota -de nuevo- un castigo notable para los partidos medios, severo para los partidos pequeños y exterminador para partidos significativos que llegan a conseguir más de 200 mil votos ${ }^{55}$. Por otro lado, estos partidos emergentes están sometidos al estrés de un plus de factor matemático desequilibrante, que supone el hecho de poder bajar de determinado porcentaje de votos ("porcentaje electoral de quiebra") en una siguiente elección, y que sobredimensiona la desproporcionalidad, produciendo un inmediato "efecto electoral guillotina"56.

Las elecciones habidas desde 2015 demuestran que si bien el sistema habilita la entrada de partidos nacionales medios (después de casi cuatro décadas), lo hace de manera notablemente desproporcionada y precaria.

b) Los efectos políticos de la desproporción

La doctrina clásica apela al factor "gobernabilidad", en ambos dos casos de desproporcionalidad, ya sea mayoritario o proporcional corregido. De esta manera millones de ciudadanos ven reducida su capacidad de influencia de manera exponencial y multinivel. Estamos ante un "modelo representativo dual" que genera por un lado estabilidad consorcial lineal para un conjunto ciudadano "A" y que, por otro, genera decrecimiento exponencial para una serie de conjuntos ciudadanos " $X$ ". La estabilidad lineal vs. decrecimiento exponencial

${ }^{55}$ El coste del escaño del PSOE (56.601) y del PP (56.708) primó a su electorado en una escala aproximada de 1.5/2/3/4 respecto al electorado de Vox, UP, Cs y M.P. Partidos emergentes con centenares de miles de votos detrás quedan fuera de representación (caso de Pacma, con 228.856).

${ }^{56}$ Según la fórmula matemática y otros factores este porcentaje puede variar. En España tal cual es su actual configuración -y partiendo de porcentajes nacionales- es grave a partir de $15 \%$, muy grave en torno al $-10 \%$ y letal por debajo del $-3 / 5 \%$. La mayor parte de considerandos cuantitativos y la mayoría de los cualitativos están analizados con recurrencia desde hace décadas (v. gr. Rose,1983, "En torno a las opciones en los sistemas electorales..."). 
es visible en la serie de ecuaciones producidas por la prima o por el castigo de la técnica electoral:

- Un partido estabilizado ("A") -de forma automática- consigue sumar los siguientes tres factores de prima lineal: 1) Ecuación institucional: mayor capacidad de decisión ejecutiva, mayor capacidad de gestación legislativa, mayor capacidad de extracción (designación) institucional; 2) Ecuación social: mayor presencia en los mass-media, mayor capacidad de penetración en el tejido civil primario (educación) y en el tejido asociativo económico; 3) Ecuación económica: mayor capacidad de financiación, que incluso se hace de crecimiento exponencial. En buena lógica dicha suma estabiliza su capacidad de determinación, socialización y sistema de clientelas y, como resultado, su ordinaria estabilidad lineal.

- Un partido emergente (“X”) -sin representación o con incipiente representación- es penalizado directamente con la suma de "dos factores de decrecimiento exponencial": 1) deja de percibir los réditos políticos anteriores (prima lineal) o los recibe con un grado con desproporción variable; 2) por el contrario aumentan sus problemas de financiación ante los costes sobrevenidos, que se hacen pasivos financieros insoportables en los casos de partidos que no logran representación, la logran en un grado mínimo, o bien tiene una reducción notable en su representación bajo el efecto guillotina ${ }^{57}$. En este último caso es donde se da el efecto más perverso, en un partido emergente en una primera fase, que se hace ascendente en una segunda fase, y que, por lo tanto, construye un aparato logístico y técnico en correspondencia a las necesidades de dicho ascenso. Una bajada hacia la franja 7\%-14\% le reduce la representación en porcentajes del anterior efecto "decrecimiento exponencial”, y lo sitúa en graves problemas de financiación y logística, convirtiéndolo en "partido precario" $^{58}$.

Incluso pudiéndose dar el caso de desaparición y/o desnaturalización del partido político bajo dos tipos de efectos:

\footnotetext{
${ }^{57}$ Respecto a financiación privada, y en financiación pública. En nuestro sistema electoral (como en la mayoría de ellos) cuando no se logra representación no se percibe un solo euro de compensación de gastos. En este sentido hay una nueva discriminación entre el valor de los votos con representación y los votos sin representación. Compensación electoral por escaño y voto para los ya primados por la técnica lectoral y ausencia de compensación al resto de ciudadanos (Ley Orgánica 8/2007, sobre financiación de los partidos políticos, art. 3).

${ }^{58}$ El caso de partidos como U.P. o Cs, considerando las dos elecciones generales 2019, y elecciones autonómicas 2019-2020.
} 
- Asimilación-neutralización del partido. Tras la amenaza de los propios resultados electorales en sí mismos, y porque cada envite electoral conlleva una gregaria negociación preelectoral con otros partidos ${ }^{59}$. Y aún habría otro factor más inquietante: la acomodación personal político profesional de parte de las direcciones/cuadros de los partidos precarios dentro de un partido sistémico, que se haría segura e indefinida; coyuntura que podríamos denominar de "selección negativa de elites", invirtiendo una de las principales funciones de un partido político como es el reclutamiento optimizador de dichas elites en pos del bien común ${ }^{60}$.

- Quiebra técnica. Conlleva la desaparición del partido y el desarraigo de miles de votantes y militantes que pasan a la abstención o a la asimilación por otros partidos de un aparente mismo sesgo político ${ }^{61}$.

En cualquiera de los dos casos se da una consecuencia perversa: la inviabilidad de la formación (veto sistémico orgánico) o la desnaturalización de la voluntad del militante y del votante (veto sistémico sustantivo).

c) La causa sistemática

Obvia. En lo que respecta a Estado y sociedad nada es inocente, y un sistema electoral en relación con dichos ítems, Estado y sociedad, tampoco. Partidos muy consolidados históricamente atienden a intereses de estabilidad del statu quo: económicos, sociales y políticos ${ }^{62}$. Por lo tanto, el statu quo apela a la

59 Ese sería el caso de múltiples formaciones políticas de ideología socialdemócrata o democristiana -algunas de ricos matices- que acabarían disolviéndose/integrándose en las dos grandes naves nodrizas del sistema español (AP/PP-PSOE), incluido el proceso de desintegración de U.C.D. (Vallés, 1986, "Sistema electoral y democracia...", pp. 19-20).

${ }^{60}$ En este sentido nunca sobra la referencia clásica de esta endemia, incluido su contundente subtitulado (tratado de Robert Michels, con data en 1915: Los partidos políticos. Un estudio sociológico de las tendencias oligárquicas de la democracia moderna).

${ }^{61}$ El caso reciente (en España) de UPyD, en función del alto coste del escaño (múltiplo de cinco en las elecciones de 2008 y de 2011), sumado al efecto desestabilizador contextual del mencionado coste; o ya, desde los orígenes preconstitucionales (elecciones generales de 1979), los casos de Unión Nacional, después de un coste por escaño de 378.964 votos $(2,11 \%)$, o del Partido del Trabajo de España y de la Organización Revolucionaria de Trabajadores, sin representación de sus 192.798 votos y de sus 127.517 votos respectivamente. Y como hipótesis, mantener la posibilidad de un decurso semejante a corto plazo para el partido Ciudadanos.

62 Esta consideración milita en la tesis de la influencia determinante de los grupos de presión en los partidos políticos y, por ende, en una gran devaluación de la representación. No es este lugar para su mención, pero sí para su recordatorio, referenciando el supuesto en toda una infinita escuela crítica clásica interdisciplinar; desde el pensamiento decimonónico (v. gr., Marx, Proudhon, Kautsky, Costa...) a la doctrina crítica del pasado siglo (Michels, Sombart, Heller, Wright Mills, Meynaud, Finer, Marcuse, Ferrajoli, Stiglitz...) y referencias del nuevo siglo XXI (Estefanía, Krugman, Ziegler, Gargarella, Crouch...). Se me hace necesario volver a repetir la cita de Soros por parte de Joaquín Estefanía: "Los mercados votan cada día, obligan a los 
gobernabilidad como metodología de adocenamiento político respecto a la ya mencionada lógica de mercado. Ello tiene su mejor plasmación funcional en la presencia de dos grandes partidos y un resto de formaciones bisagra de adaptable textura política ${ }^{63}$. Un sistema de "bipartidismo imperfecto" con dos características formalmente distantes, pero, sin embargo, absolutamente complementarias: a) sustancial alta complicidad, respecto a su espacio sistémico de consorcio (habitus negativo de coalición ${ }^{64}$ ); b) histriónica alta competitividad, intramuros de su institucionalidad ${ }^{65}$.

Para la perpetuación de este sistema de "bipartidismo imperfecto" se hace imprescindible un sistema mayoritario o bien un sistema de progresividad reducida. Todo ello sumado, lógicamente, a otros elementos de control mediático-financieros.

\section{B) Dos elementos técnicos para el voto universal real}

Dos elementos técnicos clásicos, muy formulados y con casuística.

a) Proporcionalidad pura

gobiernos a adoptar medidas ciertamente impopulares, pero imprescindibles. Son los mercados los que tiene sentido de Estado". Sigue Estefanía su reflexión haciéndose una pregunta casi retórica: "¿para qué votar, para que participar si lo más importante -la política- está predeterminada por unos poderes aleatorios -los mercados- que eliminan la capacidad de soberanía de un país? El mercado global va suplantando al poder tradicional de los Estados(...)Los gobiernos se sienten incapaces de controlar la volatilidad de los mercados financieros, lo que pone en cuestión el concepto de soberanía y, en última instancia, de democracia". La anterior percepción tiene data anterior al crack de 2008 (Estefanía, 2000, El poder en el mundo...", pp. 48-54).

${ }^{63}$ Esta premisa vigente dese el ya mencionado paradigma de Huntington y su Informe a la $1^{\underline{a}}$ reunión de la Comisión Trilateral alertando sobre los peligrosos "excesos democráticos" (Huntington, 1975, The Crisis of Democracy. Report...). Por otro lado, también hay apelaciones a la gobernabilidad, y a la necesaria modulación democrático-electoral, desde otras distintas posiciones estratégicas (v. gr., Flisfisch, 1989, Gobernabilidad y consolidación democrática...).

${ }^{64}$ Dos formas diametralmente opuestas de enfocar la naturaleza y fines de la coalición. En el modo de consorcio político estaremos ante un acuerdo de partidos para la consecución de objetivos de exclusiva prima económica individual, grupal y clientelar, distantes o ajenos al interés público. Por el contrario, en el modo de consenso político estamos ante un acuerdo de diversas fuerzas políticas para la consecución sumada de objetivos de interés general amplio.

${ }^{65}$ Para el caso de España, a partir del estudio de Gunther \& Sani, \& Shabad (1986, El sistema de partidos políticos en España...), ya se atisbaba hace 35 años la conformación de un sistema de cuatro partidos ( 2 hegemónicos +2 territoriales), de fragmentación calculada, de alta competitividad hacia dentro y fuerte cordón sanitario hacia fuera. En este sentido -35 años después del anterior estudio- el líder del segundo partido hegemónico acaba de corroborar el radical pliego de intenciones del bipartidismo connotando a la representación ciudadana sobrevenida como la tragedia mayor de la última década (Pablo Casado: "el multipartidismo es lo peor que ha pasado en diez años", La Vanguardia, 6, abril, 2021). 
Poco hay que decir porque el instrumento técnico lleva décadas inventado. A través de dos campos de actuación ${ }^{66}$ :

- La técnica proporcional en una de sus variantes más milimétricas daría por sí mismo una proporcionalidad pura -sin suelo (porcentaje de cribado), y circunscripciones de amplitud suficiente-. En este sentido sería el cociente Hare/Niemeyer, sin porcentaje de cribado; con circunscripciones amplias que respetaran, a dúo, una máxima proporcionalidad y cuestiones de territorialidad cuando las hubiere, como sería el caso español bajo estructura autonómica ${ }^{67}$.

- La técnica proporcional mixta o personalizada -cuando recoge los restos de manera milimétrica- también se acerca a una proporcionalidad pura. $Y$ además asumiría el "valor proximidad- responsabilidad/representadorepresentante" a través de la adopción parcial de distritos uninominales ${ }^{68}$.

b) Aumento notable del número de representantes a través de la eliminación del sistema bicameral.

El aumento del número de diputados es una exigencia lógica porque es un factor básico para la proporcionalidad. Máxime en países como España en donde se mantiene una de las menores relaciones entre número de diputados/población. El número de diputados no debe ser tabú porque hay países como Alemania en donde puede ser oscilante en cada una de las elecciones. Tampoco debería ser tabú el coste institucional porque para salvarlo habría una solución: la eliminación de una cámara vacua como el Senado, adornada habitualmente de una hiriente desproporcionalidad representativa y sin ningún valor como cámara de representación territorial. 0 lo que es peor, a cargo de una única función sustancial, como es la suspensión/intervención de competencias y derechos de la estructura territorial

${ }^{66}$ Campos de actuación que deberían conllevar reforma constitucional, como sería el caso español (arts. 68-69, y los artículos afectados indirectamente).

67 Vid., Soriano, 2018, "El sistema electoral del Congreso de los diputados...", en tablas comparativas al respecto. Facturadas desde la fórmula Saint Lagüe que prácticamente consigue una proporcionalidad casi semejante a Hare. La proporcionalidad lograda alcanza una tasa de 98,525\%; e incluso 99,525\% en circunscripción única y ajuste territorial de número de diputados.

${ }^{68}$ En este modelo -si es respetada la cuantificación de la bolsa de restos para la asignación de escaños de partido- el único corrector de proporcionalidad será: a) el porcentaje de cribado (en la RFA el 5\% del total); b) la propia técnica de proporcionalidad (en la RFA se ha estructurado con Hare y también con Saint Lagüe); c) la posibilidad de prima, a través de un factor de corrección de mandatos excedentes. Este sistema -con algún factor de corrección- se encuentra en la RFA, así como en países como Bolivia, Eslovenia y Venezuela, los cuales tiene en común una fórmula de corrección/prima de base étnica (Vid. Palacios, 2018, p. 32). 
(v. gr., art. 155 C. E.), a modo de "alquimista institucional" último del bloque de constitucionalidad $^{69}$. La resta de senadores en España sumaría la posibilidad de 615 diputados $(350+265)$. Realmente no haría falta llegar a tal número y podría garantizarse una proporcionalidad sin distorsión alguna con 400-500 diputados ${ }^{70}$.

El bicameralismo es en general un sistema de duplicidad representativa que no suele tener un factor de ingeniería creativa territorial sino más bien de deconstrucción representativa, generando sistemas competenciales simplemente más complejos, equívocos y densos, pero no más eficaces. El caso de la Constitución Española es uno de los casos más significados en este sentido, sobre todo en cuanto a la mencionada vacuidad, sólo superada por la Cámara de los Lores cuya vacuidad se complementa con un historial discriminatorio extremo ${ }^{71}$. Prueba de la funcionalidad del unicameralismo es como hay más de un centenar de países unicamerales, entre los que se encuentran Estados muy homologables desde el análisis de cualquier perspectiva $^{72}$.

\section{Mantra de la ingobernabilidad vs. cultura cívica consensual y canales de institucionalidad}

La conclusión del anterior capítulo -reivindicando la igualdad sustancial ideológica del sufragio- suponía en el caso español una única cámara con hasta incluso 500 diputados, con un nivel de proporcionalidad del 99\%. Suponía aumentar el número de fuerzas representadas, potenciar a los partidos intermedios y sostener a las formaciones pequeñas. En definitiva, desarrollar algo democráticamente eucarístico: el voto igual sin discriminación ideológica.

\footnotetext{
69 Elementos varios en este sentido para el caso español en: Sáenz, 2012, "Parlamento, partidos y Estado autonómico....".

70 El índice de proporcionalidad en nuestro trabajo de referencia se puede situar en 99,5 contemplando un Congreso de 400 diputados (Soriano, 2018, "El sistema electoral del Congreso de los diputados...", p. 107).

${ }^{71}$ Incluso cuando el fin bicameral podría resultar enriquecedor desde una perspectiva territorial (v. gr. cantonalismo en Suiza o municipalismo en Francia) pero, sin embargo, ningún modelo ha sido capaz de acotar creativamente el ámbito competencial y/o su gregarismo respecto a la primera cámara.

${ }^{72}$ V. gr. Croacia, Dinamarca, Hungría, Islandia, Noruega, Nueva Zelanda, Portugal, Suecia o Finlandia.
} 
Por el contrario, los partidarios de la teoría de la ingobernabilidad suelen argumentar en contra de la mayor proporcionalidad bajo cuatro supuestos en torno a una hipotética parálisis institucional y desestabilización social general: 1) Perturbación electoralista, al obligarse a repetir nuevas elecciones tras el bloqueo de la investidura, con el consiguiente trastorno de funcionamiento político-social ordinario, así como un coste económico notable; 2) Dificultad pre-institucional, al no poderse canalizar la investidura del presidente del gobierno; 3) Bloqueo post-institucional legislativo, por la dificultad de alcanzar mayorías ordinarias, 4) Bloqueo post-institucional orgánico, por la dificultad de alcanzar mayorías cualificadas para la conformación de altas instituciones del Estado o de importantes instancias orgánicas.

A una propuesta de neutralización de esos 4 supuestos se dedicarán los epígrafes siguientes:

\section{A) La perturbación electoralista en tres falsos mantras}

La repetición electoral no tiene porqué ser una consecuencia de la proporcionalidad si existe una cultura cívica de consenso y canales técnicos para una institucionalidad funcional. No obstante, aun en el caso de tener que repetir procesos electorales ("bucle electoral"), estos no tienen que suponer un quebranto en sociedades medianamente estables sino, más bien al contrario, ser instrumentos oportunos para una mayor pedagogía política y constitucional respecto a la ciudadanía.

La repetición de elecciones en un breve plazo de tiempo suscita cuatro falsas impugnaciones:

a) Alto coste económico

Se podría decir que un proceso electoral es asimilable como teología política a la eucaristía en el hecho religioso. Es decir, es un hecho sustancial central. El coste de unas elecciones ordinarias es insignificante para el Estado en una democracia de mediana complejidad ${ }^{73}$. Exactamente en España las elecciones

\footnotetext{
${ }^{73}$ Sin embargo, el argumento del "insoportable gasto" se encuentra muy interiorizado, valga el ejemplo de como en una jornada sobre Reforma del sistema electoral español. Análisis y propuestas (Universidad de Zaragoza/FMGA; 30/11/2017) fue el principal argumento negativo de tres altos funcionarios responsables de la organización electoral en la Comunidad Autónoma.
} 
de 2019 (noviembre) suponían 138,9 millones de euros, el 0,031\% de los Presupuestos Generales del Estado de 201974. Compárese dichas cifras y porcentajes con los de otras partidas presupuestarias, o cuantificación de índole tributaria, ya sea activa o pasiva ${ }^{75}$.

b) Parálisis de la acción de gobierno

La acción de gobierno no se paraliza. Lo demuestra el funcionamiento estable del gobierno en funciones-administración en este mismo país durante lapsos largos sin un solo quebranto digno de mención; o los más continuados gobiernos provisionales de un país tan estándar como Bélgica. Es sólo el Gobierno el que queda en funciones; por lo tanto, secretarios de Estado, subsecretarios, secretarios generales, secretarios generales técnicos 0 directores generales están en pleno uso de sus atribuciones hasta su cese por el Consejo de ministros. Además, en nuestros sistemas institucionales hay una inercia administrativa -para bien o para mal- que blinda al modelo de un decaimiento abrupto del estado de $\operatorname{cosas}^{76}$.

Las Constituciones no suelen limitar las competencias de los gobiernos en funciones. En España se paralizan determinadas actuaciones regladas, de poco valor operativo durante un impasse electoral (disolución de las cámaras, cuestión de confianza, referéndum consultivo), o más sustanciales como ley de presupuestos, delegación legislativa o proyectos de ley. La Ley del Gobierno otorga un margen amplio de actuación para el resto de posibles medidas más allá del despacho ordinario de asuntos públicos, con base en una "concepción funcional volátil" tal como la urgencia o el interés general, que han dado cabida al recurso del decreto-ley, justificada su "urgente necesidad" -esta vez sí- sobre la base de la incapacidad legislativa del Gobierno en funciones a lo largo de lapsos extraordinarios ${ }^{77}$.

\footnotetext{
${ }^{74}$ Supusieron 138,9 millones de euros, incluyendo gastos ya estructurados, como los del funcionariado, que suponen la mayor partida (Ministerio de Hacienda, 2019, Orden por la que se fijan las cantidades de las subvenciones...). Los P.G.E. de 2019 se establecieron en 449.739 millones de euros (Secretaría de Estado de Presupuestos y Gastos, Estadísticas 2011-2019...).

${ }^{75}$ Por ejemplo, el coste económico-tributario que suponen los incentivos tributarios al alquiler, cifrados en una pérdida de recaudación anual de 1.039 millones de euros (AIREF, Evaluación del gasto público 2019...).

${ }^{76}$ El gobierno Rajoy estuvo 314 días (2015-2016) en funciones, el gobierno Sánchez 254 días (2019-2020). El gobierno de Bélgica llegó a estar 541 días en funciones, en donde se tomó incluso la decisión de atacar militarmente Libia.
}

${ }^{77}$ Ley del Gobierno (art. 21). 


\section{c) Desestabilización económica}

No se ha percibido ninguna desestabilización económico-social por lapsos de gobiernos en funciones, en ningún país de Europa. Por dos razones (un dato y un argumento):

- No coinciden con ninguna crisis de crecimiento, de aumento del desempleo o incluso de caídas notables del mercado bursátil; ya que dichas crisis han venido dadas por el deficiente funcionamiento de la economía financista, como la última crisis de 2008.

- Al sistema -al que antes aludíamos en boca de Stiglitz o de Estefanía- no le suele inquietar una coyuntura técnica de gobierno en funciones sino el tipo de coyuntura política, es decir qué tipo de gobierno hay o puede llegar a haber. Hasta tal punto que la coyuntural inestabilidad institucional no ha pasado por "inestabilidad constitucional", al incluso darse una mejora de casi todas las magnitudes económico-sociales ${ }^{78}$.

\section{d) Perturbación social-cultural}

En principio sí habría un elemento de perturbación social, como son las histriónicas campañas electorales en la lógica del mercadeo (merchandising tie-in). Una performance impuesta y no una deliberación asumida e interiorizada que cuando se repite en un breve lapso termina hiriendo la sensibilidad de la ciudadanía ${ }^{79}$. Sea dicho esto desde la perspectiva condicional de cómo una democracia no lo es sin capacidad formativa e informativa sustancial del ciudadano; y al ciudadano no se le ha socializado en una base pedagógica o deliberativa básica.

No obstante, en este aspecto pedagógico-deliberativo sí se da una coyuntura muy favorable a partir del bucle electoral. Por encima de la performance

\footnotetext{
${ }^{78}$ Como ejemplo el caso de Bélgica -record gubernamental en funciones- todas las magnitudes económicas mejoraron: caída del paro, aumento del Pib/Pib per cápita, reducción del déficit y aumento del salario mínimo interprofesional (La Información, 2011, "Bélgica: 500 días sin Gobierno..."; en idéntico sentido, en comparativa europea (Libre Mercado, 2018, "Se repite la historia de Bélgica y España: Alemania, crecimiento..."); en relación al caso de España: BBVA Research, 2016, "Situación España. Cuarto...".

${ }^{79}$ La proclama monocorde, la descalificación grosera, la omnipresente megafonía itinerante, los paneles fotográficos y la parafernalia cromática sustituyen cualquier lectura, argumentario 0 debate cualificado. Desde los años setenta no han dejado de utilizarse instrumentos para la banalización y enmascaramiento del discurso político. Sirva de recordatorio que ha pasado medio siglo desde el tratado clásico de Parkinson, en donde de manera textualmente explícita habla de "tuercas y tornillos" para aludir a la estrategia de campaña (Parkinson, 1970, Winning Your Campaign: A Nuts...").
} 
electoral, el hecho de una repetición electoral -con decenas de semanas de impasse para la formación de gobierno- si es un tiempo extremadamente positivo para el aumento exponencial de la capacidad deliberativa social. Una parte notable de la población se introdujo en elementos de construcción deliberativa sustanciales tales como: la mecánica exacta de una investidura, las lógicas de formación de gobierno en funciones, la configuración de pactos y consensos y, sobre todo, las líneas de convergencia o divergencia entre uno u otro programa electoral; así como también respecto a de que maneras se dirimían compromisos políticos más ajustados. Todo este último proceso es la antítesis del histriónico ruido del merchandising electoralista.

B) Dificultad pre-institucional. La difícil investidura del gobierno vs. cultura del consenso y del pacto de gobierno

La proporcionalidad y el voto igual también dificultarían la investidura del presidente y, por lo tanto, la formación de nuevo gobierno. Evidente. Una mayor proporcionalidad hace más compleja la investidura, la formación de un gobierno y la factura del programa de gobierno. A eso se le llama dinámica de acuerdo, negociación, consenso y, en definitiva, capacidad para trasladar a las políticas públicas el voto igual de la ciudadanía. Es decir, democracia.

La coalición y los gobiernos complejos han estado presentes en toda Europa desde finales de la II GM, y fueron pieza clave en la conformación del Estado social durante los siguientes 35 años. Incluso a partir de la deconstrucción del Estado social (1980), siguen presentes dichos mecanismos de acuerdo. El hecho es que actualmente en la Unión Europea hay 23 Estados (de 27) bajo gobiernos de coalición, de los cuales 17 están compuestos de tres o más partidos $^{80}$; además de la especificidad del modelo consociacional suizo ${ }^{81}$.

a) La banalización del consenso: España como ejemplo

España ha sido durante el último casi medio siglo un país nada dado a coaliciones de gobierno nacionales, y de hecho todos los gobiernos habían sido

\footnotetext{
${ }^{80}$ Hay gobiernos de una complejidad política notable, con fórmulas de hasta 7 y 6 partidos (Bélgica, 7 partidos; Italia, 6; Francia, 6; Finlandia 5; Letonia, 5; Países Bajos, 4; Rumanía, 4).

${ }^{81}$ El caso de Suiza dentro del modelo del consociacionalismo -por definición para sociedades complejas (religiosas, lingüísticas o étnicas)- puede servir también para explorar las posibilidades de una cultura de consenso (y gobernabilidad) "ideológico" en un modelo de representación proporcional pura, bajo la incardinación constitucional del modelo de Estado. En este sentido obsérvese también las propuestas del nuevo constitucionalismo latinoamericano (Bolivia, Ecuador).
} 
monocolores hasta el gobierno actual. Tampoco se hicieron pactos de investidura/gobierno desarrollados, publicitados y transparentes en su factura y desarrollo ${ }^{82}$.

En España durante el lapso transcurrido desde 2016 (XI legislatura, 13 de enero de 2016) a la actualidad, se han desgranado descalificaciones políticas permanentes en torno: a) complejidad de las fuerzas de apoyo a la investidura; b) formación de un gobierno de coalición; c) textura ideológica de dicho gobierno. En este último lustro la descalificación del consenso -y más concretamente la del actual gobierno de coalición- se ha hecho prácticamente un dogma. Descalificaciones o posiciones hostiles que cubrieron todo el espectro ideológico, llegándose a una expresión -“Gobierno Frankenstein"- que resume todo el cuadro de diagnóstico crítico $^{83}$. Con posiciones iniciales pertinaces de "suma cero" 84 ; o, posteriormente a la coalición, con descalificaciones de política kitsch como "Gobierno bolivariano independentista" (en sus múltiples versiones) proferidas en todas y cada una de las sesiones de control parlamentario desde la formación de gobierno ${ }^{85}$. Incluso algo menos conocido: desde posiciones doctrinales de izquierda alternativa ${ }^{86}$. Todo ello hablaría de la nula cultura de consenso existente en España, salvo en coyunturas de fuerza mayor sobrevenidas ${ }^{87}$.

\footnotetext{
${ }^{82}$ En este sentido sirva como ejemplo el Pacto del Majestic (1996), pacto de grandes contenidos que supuso la investidura del presidente Aznar y del presidente Puyol, posibilitando la captura del poder por parte de ambos partidos en espacios políticos y territoriales perfectamente deslindados y repartidos; en una legislatura donde se acometió la más notable reestructuración económica y territorial sustancial del Estado. Pacto sin publicidad ni escrutinio público en lo que serían grandes e importantes desarrollos normativos y de políticas públicas.

${ }^{83}$ Expresión despectiva respecto a una hipotética investidura de apoyo múltiple (ni siquiera respecto a un gobierno de coalición) proferida por el ex vicepresidente Pérez Rubalcaba (junio, 2016), cuando podría producirse dicha investidura del candidato del PSOE sólo con los votos de tres partidos más (Podemos, CDC y PNV).

${ }^{84}$ La vicepresidenta en funciones Carmen Calvo, negando la posibilidad de gobierno de coalición, afirmaría como la única vía para evitar una repetición electoral sería que Unidas Podemos aceptara las 300 medidas aprobadas por la dirección federal del PSOE (La Sexta/Europa Press, 2019, "Carmen Calvo descarta el Gobierno de coalición...").

${ }^{85}$ Desde el Real Decreto 8/2020 (12 de enero) por el que se nombran Ministros del Gobierno, y en todas y cada una de las sesiones de control parlamentarias del primer semestre, y en casi todo el resto de sesiones de control hasta la actualidad (abril, 2021).

${ }^{86}$ En este sentido la monografía de Martín Seco (2020, "Una historia insólita. El gobierno Frankenstein..."), bajo supuestos muy diferentes a los anteriores, y con hipótesis plausibles en lo que respecta a lealtad programática.

${ }^{87} \mathrm{Sin}$ embargo, la irrupción de partidos de gran fuerza emergente (Podemos, Ciudadanos, Vox, junto con otras fuerzas localistas) ha obligados a configurar sub modelos de coaliciones autonómicas desde el último lustro, siendo 13 comunidades autónomas las que ahora están bajo gobierno de coalición. Mayorías inconsistentes en función de la precaria cultura política consensual. Inconsistencia derivada de varios factores: la poca capacidad para la imbricación 
b) Bases teóricas de una fórmula muy experimentada. La ley de proporcionalidad de Gamson

Desde hace sesenta años está inscrita la posibilidad en torno a la factibilidad -o no perturbación- de trasladar los votos/escaños de un parlamento a la formación de gobierno, y a un desarrollo institucional y legislativo dinámico. Son más de sesenta años con gobiernos de coalición en toda Europa. Desde la inmediata postguerra la casi práctica totalidad de países europeos asumieron coaliciones de gobierno, incluso coaliciones muy complejas dotadas de una gran proporcionalidad en el reparto de competencias ministeriales, paquete legislativo y combo normativo (portfolio payoff). Hablamos de hasta 13 países con una representación muy fragmentada que, como se apuntaba antes, fueron clave para el consenso y configuración sobre el modelo social de Estado. Por lo tanto, la coalición no sólo no es una novedad/excentricidad, sino que hay una experiencia y un bagaje detrás; con análisis sobre su constancia y método a partir del que debiera ser clásico estudio de Gamson, que da nombre a dicha mecánica y a dicha cultura como ley de proporcionalidad de Gamson, o incluso a una muy básica teoría sobre la formación de coaliciones ${ }^{88}$.

La ley de Gamson fue posteriormente recogida de manera más concreta como teoría sobre la experiencia de la configuración del modelo de gobierno de coalición en la Europa de postguerra con una correlación en la proporcionalidad superior a 0,90 . Se constataba la proporcionalidad entre representación numérica en un gobierno y escaños parlamentarios. Cada partido en el gobierno recibe una recompensa proporcional al peso en el que contribuye a la coalición. Incluso hay una sobre tasación de las pequeñas formaciones que reciben bonificaciones más allá de su aportación parlamentaria en la lógica política mancomunada que supuso la construcción del Estado social ${ }^{89}$.

Hay 5 consecuencias positivas de una cultura de la coalición, tal y como se conformó en la cultura política europea de postguerra:

1) Transparencia programática. Mayor claridad de las propuestas y políticas de los diferentes partidos respecto al oscurantismo que suelen tener los simples

de políticas públicas, estrategias conspirativas de captación, o por la simple absorción de alguna/s fuerzas minoritarias por la fuerza gubernamental dominante.

88 Diez escuetas páginas en Gamson, 1961, "A Theory of Coalition Formation...".

${ }^{89}$ Browne \& Franklin, 1973, "Aspects of Coalition Payoffs in European...", en el estudio sobre gabinetes de 13 países distintos. 
pactos extra gubernamentales entre las distintas fuerzas parlamentarias. Partiendo de la existencia de un pacto de gobierno claro, detallado y divulgado.

2) Poder real institucional. La suma/concentración de fuerzas políticas en el gobierno encierra más poder real político, a través de una mayor capacidad de cohesión/resistencia respecto a las intimidaciones y chantajes políticos a-institucionales procedentes de los grupos de presión.

3) Gobernanza. Mayor flujo de penetración comunicacional a los grupos de interés legítimos, ya que estos habitualmente tienen canales de demanda abierta con los partidos políticos.

4) Afección constitucional. Escasa desafección institucional ciudadana al verse una mayor parte de la población representados en sus intereses, con una movilidad social ascendente alta.

5) Control. Mayor sistema de control entre los miembros de la propia coalición. Lo que podría parecer una afuncionalidad de gobierno -la discrepancia privada o pública sobre medidas a tomar- no deja de ser una garantía institucional de control equiparable (o mayor) al control parlamentario.

A partir de la deconstrucción del Estado social (1980) se observarán serios correctivos en la proporcionalidad sustancial en función de cómo partidos con vis hegemónica (formateur parties) asumirán sin excepción las carteras prominentes ${ }^{90}$. También es muy importante apuntar como desde la mencionada deconstrucción del Estado social la cultura del "consenso" político ha pasado a convivir con una progresiva cultura del "consorcio" político ${ }^{91}$, quedando, no obstante, aspectos básicos de la cultura del consenso y de la coalición en una parte de Estados europeos.

c) La insuficiente grafía del consenso en la cultura constitucional

No existe desarrollo normativo en ese sentido sino un ejercicio más de constitucionalismo omisivo. El artículo 99.2 de la Constitución preceptúa la obligación de exponer un programa de gobierno para la investidura. Tres

\footnotetext{
${ }^{90}$ Warwick \& Druckman, 2005, "The missing piece: Measuring portfolio salience...".

${ }^{91}$ El ejemplo de Italia sería un pionero caso extremo que ilustra esta deriva. Justo a partir de la mencionada deconstrucción del Estado social (1980) se inaugura una década de un sistema de gobierno consorcial (concierto para delinquir), bajo el Sistema Pentapartito/Tangentopoli (19811990). El pentapartito (1981-1991) es ejemplo extremo del consorcio al abarcar casi todo el arco ideológico, desde el conservadurismo al socialismo (Partido Democracia Cristiana, Partido Socialista Italiano, Partido Socialista Democrático Italiano, Partido Liberal Italiano y Partido Republicano Italiano). En un sentido más general los propios informes de la U. E. (v. gr., Comisión Europea, 2014, "Informe sobre la lucha contra la corrupción...".
} 
palabras que como todo texto constitucional breve no concretan ni la cualidad ni las especificaciones que debería contener un texto de esa importancia. No hay protocolización ${ }^{92}$.

Tres palabras que valen tanto para una investidura por mayoría absoluta como para una investidura por mayoría simple, así como valen tanto para un gobierno monocolor como para un gobierno de coalición. En puridad democrática un programa de gobierno debería ser un discurso apoyado en un texto suficientemente específico. En mayor medida lo debería ser cuando la investidura se consigue sumando votos de fuerzas dispares. Y debería ser aún más detallado como documento de formación de gobierno de coalición, con los compromisos legislativos asumidos, las medidas normativas más sustanciales y la memoria económica donde sustentarse. Aunque sólo fuera una "protocolización institucional" no sujeta en la propia Constitución (o en su caso en los Estatutos de Autonomía), que obligara a la redacción de un texto con elementos programáticos tasados. O bien la garantía secundaria de una ley especial al respecto, pudiendo ser una ley del gobierno con mayor "desarrollo programático primario", concretando dicho pacto de gobierno de manera lo más pormenorizada posible ${ }^{93}$. Por ello, es posible hablar de insuficiente grafía del consenso y del propio contrato democrático.

C) La superable dificultad de la funcionalidad institucional: la opción del parlamentarismo negativo de mayoría relativa

En el punto anterior se establecía como una cultura del consenso puede amparar la gobernabilidad de un sistema de representación de proporcionalidad pura. ¿Pero qué ocurre si la capacidad de consenso es débil o está debilitada? ¿Es entonces viable un parlamento multi-fragmentado para la elección de presidente, aprobación de leyes o nombramiento de instituciones de control? La respuesta es sí, como se enunciaba al principio del capítulo. Estableciendo un modelo institucional corregido, que dirá rompe el principio de mayoría y proporcionalidad. Sí, lo rompe, pero qué se hace preferible de cara al respeto al principio democrático ¿un sistema electoral "corregido" o "muy

\footnotetext{
${ }_{92}$ Así como tampoco se concreta en el Reglamento del Congreso de los Diputados (art. 171).

${ }^{93}$ Las diferentes leyes del gobierno concretan toda una planificación ex post facto a la investidura y a la formación de gobierno (desarrollo programático secundario). Concretamente en el caso español en la Ley del Gobierno se regula de manera pormenorizada como deben formularse el "Plan Anual Normativo" (art. 25) y el "Informe Anual de Evaluación" (art. 28), amén de todo el resto de elementos procedimental-garantistas desarrollados en su Título V.
} 
corregido" que impida la representación igual de la sociedad o un sistema institucional 'corregido' que limite la capacidad representativa decisoria de una previa representación igual?

La alternativa del "parlamentarismo negativo" en su modalidad de "mayoría relativa positiva" sería el mecanismo con el que evitar los supuestos problemas de gobernabilidad de una representación parlamentaria pura o igual. Desde el principio hay que advertir que esta fórmula sólo sería admisible desde un planteamiento de reivindicación de un parlamento de correspondencia proporcional pura, en donde podrían plantearse problemas de gobernabilidad al encontrarnos ante un muy fragmentado parlamento, y que es democráticamente inadmisible en parlamentos con bajos índices de proporcionalidad, ya que todavía se acentuaría más la desproporción.

Tres escenarios distintos con base en una técnica clásica.

a) La investidura de mayoría relativa con investidura cerrada de corto plazo El parlamentarismo negativo nace y se desarrolla como fórmula de reducción del control parlamentario del gobierno y, por lo tanto, de mayor hipotética estabilidad de dicho gobierno. Esta mecánica está instalada hace décadas en el acervo teórico general del Derecho Constitucional, ya desde su utilización pseudo-absolutista ${ }^{94}$; así como también para dotar de "estabilidad primada" a gobiernos minoritarios, a través de hacer prescindible la confianza del parlamento al gobierno ${ }^{95}$. Evidentemente ninguna de estas dos posibilidades es la que nos interesa.

El parlamentarismo negativo tiene otra tercera modalidad en la mencionada técnica de la "mayoría relativa positiva". Su mecánica es en principio muy básica, y por la cual el candidato o candidatos a la investidura sólo deben tener

\footnotetext{
${ }^{94}$ Los orígenes del modelo se referencian en una primera utilización histórica torticera del parlamentarismo negativo por los sistemas de soberanía compartida Es bueno recordar que el modelo sirvió en origen para unos fines radicalmente opuestos a los de este trabajo, como "modus operandi" en los estertores de los modelos de soberanía compartida; como forma de operar la transición controlada hacia modelos de soberanía nacional-parlamentaria. El rey seguía nombrando a los miembros del gobierno, aunque asumiendo en mayor proporción los resultados electorales, y la apertura de mecanismos de hipotética posible censura parlamentaria. Modelo de transición que sería visible en las monarquías parlamentarias supervivientes y ha sido visible ya sólo como "ritual" en Reino Unido, Holanda Noruega y Dinamarca, Luxemburgo en donde se "evita" la confianza parlamentaria (Fusilier, 1960, Les Monarchies Parlementaires...".

${ }^{95} \mathrm{Ha}$ sido el caso de regímenes semi presidencialistas (Francia) o semi presidencialistas "atenuados" como Portugal o Austria (vid., De Vergottini,1985, Derecho constitucional comparado...).
} 
más votos que los otros candidatos. Con ello, el problema de la dilación en la investidura (propuesta/votaciones fallidas/repetición electoral) queda evitado, y se hace imposible apelar a la falta de gobernabilidad.

El sistema constitucional español, como tantos otros, está basado en el denominado parlamentarismo positivo, en el que la investidura está configurada como de dificultad irreductible en un proceso trifásico indefinido (propuesta refrendada monárquica/mayoría absoluta/mayoría simple/nuevos procesos electorales "Xn"). Pero dicha mecánica sólo es hábil en la configuración de su orgánica nacional, ya que diferentes modelos autonómicos pueden servir de ejemplo sobre la posibilidad de establecer modelos de mayoría relativa. Esta posibilidad ha sido abierta en los estatutos o legislación "orgánica" de las comunidades de País Vasco, Asturias, Valencia, Castilla-La Mancha y Andalucía a lo largo de las últimas décadas, y que pueden servir de ejemplificación ${ }^{96}$. Incluso hay también modelos internacionales de conformación gubernamental funcional-consensuales que sirven para completar el elenco técnico ${ }^{97}$.

Un sistema de mayoría relativa albergará tres fases perfectamente funcionales:

1) Tópica. Por la que se exige al candidato una "mayoría absoluta" parlamentaria; en donde el proceso se cierra si es conseguida por un candidato. $O$ bien hay una o sucesivas votaciones para intentar lograr una "mayoría simple".

2) Funcional. O de "mayoría relativa" -una vez agotada la vía de la mayoría simple- por la que se vota a candidaturas presentadas, y es investida la candidatura más votada, cerrándose así el proceso de manera muy funcional. Esta segunda fase puede tener diversos modelos: a) se vota entre los dos candidatos más votados en la primera fase; b) se vota entre todos los

\footnotetext{
${ }^{96}$ Mediando múltiples reformas estatutarias y legislación de desarrollo, fundamentalmente las respectivas leyes del gobierno. No se pretende aquí concretar los tiempos de vigencia, y sus diversas vicisitudes -propios de un estudio de derecho estatutario- sino sólo ejemplificar sus mecánicas para la funcionalidad (racionalización) parlamentaria. Para una minuciosa disección de dichas casuísticas, vid., Bastida, 2001, "De nuevo sobre el modo de designación..." pp. 3970.

${ }^{97}$ El caso alemán sería un ejemplo de cierre casi seguro en un solo proceso electoral, tras poder pasar por las siguientes fases (Ley Fundamental de Bonn, art. 63): a) propuesta presidencial e investidura por mayoría absoluta en el Bundestag; b) propuesta del Bundestag e investidura por mayoría absoluta; c) propuestas en el Bundestag y mayoría simple; d) mayoría relativa derivada del anterior proceso (con opción alternativa del Presidente de disolución). El mencionado caso del consociacionalismo suizo puede servir también de inspiración.
} 
candidatos presentados; c) se proclama al candidato con mayor número de escaños.

3) Estabilización. No serviría la regla de la mayoría relativa para la investidura si los posteriores mecanismos de control del gobierno abrieran una más sencilla fórmula de censura al gobierno. Se daría un desequilibrio estéril y una desestabilización mucho mayor. Por lo tanto, las fórmulas de control-determinación del gobierno estarán sometidos a requisitos proporcionales a las fórmulas de investidura, bajo el denominador de ser moción de censura constructiva limitada: a) número de firmas para la interposición muy cualificado, en torno a una cuarta parte de los diputados; b) candidato alternativo, cuyo fracaso le podría inhabilitar para una hipotética segunda moción; c) mayoría absoluta de la cámara, o incluso de tres quintos; d) imposibilidad de repetir la propuesta por los mismos firmantes; e) tiempos acotados de interposición: un año hasta después de la investidura, y un año antes del término de la legislatura.

b) La mayoría legislativa relativa

La mayoría legislativa relativa tiene la misma base que la anterior: argumentar la viabilidad y funcionalidad de la proporcionalidad pura en un parlamento, en este caso para la aprobación de las diferentes leyes, fundamentalmente pensando en las leyes de presupuestos. Los hipotéticos porcentajes de voto para la aprobación legislativa por mayoría relativa ya es objeto de discusión a contextualizar, pero cabría la posibilidad de que adquirieran semejante proporcionalidad negativa respecto a la nueva proporcionalidad pura (proporcionalidad positiva) que adquiere la cámara legislativa ${ }^{98}$.

Esta hipótesis puede tener dos argumentos en contra, en la línea antes apuntada:

- Ruptura del principio de representación

Podría parecer osado apoyar la técnica de mayoría relativa para la aprobación de leyes, por considerarse que no sería representativa de la composición del parlamento. Parece este un argumento muy contradictorio, teniendo en cuenta que será utilizado por aquella doctrina que sí admite parlamentos que representen a un número desproporcionado o muy desproporcionado de

${ }^{98}$ Evitar la falta de gobernabilidad podría ser perfectamente factible con un porcentaje para la aprobación de mayoría relativa del $30 \%$ para leyes ordinarias y de $40 \%$ para leyes presupuestarias y leyes orgánicas. 
ciudadanos

en

la

ecuación

voto/representación

$(\mathrm{R}=\mathrm{V} 1 \times 10+\mathrm{V} 2 \times 8+\mathrm{V} 3 \times 3+\mathrm{VX} \times 0 \ldots)$.

Por otro lado, resulta obvio que las fuerzas políticas no representadas o sub representadas (antaño) preferirían -en cualquier caso- estar representadas ahora con todos los amplios efectos que despliega el hecho representativo (aún bajo un sistema de mayoría legislativa relativa) que no estar representadas en absoluto; sobremanera las fuerzas políticas minoritarias que obviamente preferirían existir -evitando la "muerte representativa"- con el contrapeso de aceptar un sistema de mayoría legislativa relativa.

- Ruptura del principio de mayoría

El argumento de la ruptura del principio de mayoría no puede ser válido porque es una ruptura que ya se produce con la fórmula contraria, bajo el principio de mayoría cualificada: a) mayorías cualificadas legislativas o de designaciones institucionales $(3 / 5,2 / 3 \circ 5 / 6)$ que posibilitan que diferentes minorías $(41 \%$, $34 \%, 17 \%$ ) pueda bloquear a una mayoría, rompiendo por lo tanto dicho principio de mayoría ${ }^{99}$; b) mayorías cualificadas constituyentes $(3 / 5,2 / 3)$, que hacen de la rigidez constitucional la norma en la mayoría de sistemas, bajo la decisión de una minoría de bloqueo ${ }^{100}$; c) Incluso hay un último ejemplo de ruptura del principio de mayoría en la función institucional de legislador negativo, cuando un porcentaje minoritario de parlamentarios puede instar la declarativa de inconstitucionalidad de una ley ${ }^{101}$.

c) Extracción de las instituciones sustanciales de control. Las posibilidades del proporcionalismo puro

El campo del control institucional, el campo clásico bajo la recurrente expresión check and balances o de la división de poderes sería otro espacio en el que

\footnotetext{
99 La cualificación de 3/5 está extendida en numerosos países para numerosas materias y nombramientos, pero asimismo la mayoría de 2/3 (Holanda, Bélgica, Hungría, Italia) para bastantes materias, e incluso hay ejemplos de una mayoría extrema de 5/6 (Dinamarca, en transferencias competenciales extra-nacionales). De hecho, el sistema de mayoría cualificada extrema es casi la norma en todo el sistema de "refuerzo" de la Unión Europea en la toma de decisiones.

${ }^{100}$ Incluso aún en mayor medida se produce la ruptura con el principio de mayoría en aquellas constituciones con cláusulas de intangibilidad en significadas Constituciones: Francia, Alemania o Italia.

101 Visible en la casi práctica totalidad de sistemas constitucionales la posibilidad de inconstitucionalidad de leyes a instancia de un porcentaje mínimo de parlamentarios representantes de un exiguo porcentaje electoral- o bien por parte de la jefatura del Estado, poder ejecutivo, instancias unipersonales de control, regiones, municipios, minorías ciudadanas o, incluso, por algún actor social como sindicatos o iglesias (v. gr., como ejemplo omnicomprensivo, Constitución de Polonia, arts. 191-192).
} 
poder considerar un "sistema institucional de control-extracción proporcionalizado", con base también en la proporcionalidad pura parlamentaria. Sobre tres presupuestos:

- El decurso histórico constitucional ha obviado otras posibilidades complementarias de elección de las instituciones de control (las asimilables a tribunal constitucional, consejo general del poder judicial/tribunal supremo, defensoría del pueblo, tribunal de cuentas, ministerio fiscal) que no sea su elección directa o indirecta por parte del poder ejecutivo y legislativo ${ }^{102}$.

- Las instituciones de control llevan toda la historia constitucional siendo designados en circuito cerrado institucional por los poderes ejecutivo y legislativo, ya sea directa o indirectamente; en clara y pertinaz posición contradictoria histórica con lo preceptuado por el tan citado Madison ("El Federalista") como teórico central de la división de poderes ${ }^{103}$.

Actualmente casi todas las instituciones de control en Derecho comparado son designadas por dichas mayorías en técnica de cupo cerrado, ya sea parlamentario, en combinación con el cupo del poder ejecutivo o del jefe del Estado, o bien de manera mixta a través del reparto de cuota entre todas estas instituciones; incluso en los casos más graves bajo el diktat de una sola institución unipersonal como el jefe de gobierno o de Estado. Todas las anteriores mecánicas ponen los nombramientos del eje del check and balances a disposición del partido hegemónico (decisión unipersonal) o a disposición de los dos partidos mayoritarios (decisión hegemonista), en una vulneración severa de la lógica sustancial de la división de poderes ${ }^{104}$.

\footnotetext{
${ }^{102}$ Elección parlamentario-partitocrática que ha negado otras posibilidades complementarias de elección, tal como la elección directa popular, la elección gremial/corporativa o la elección insaculatoria. Métodos de elección estos que combinados -sumada la extracción institucionalhabilitarían una real separación de poderes sobre previos criterios de mérito y capacidad (en este sentido, vid., Palacios, 2014, "Del proceso destituyente al debate constituyente...", pp. 268 y ss.).

103 "Constituido (el Estado) de tal manera que los miembros de cada uno de ellos tengan la menor agencia posible en el nombramiento de los miembros de los demás. Si se cumpliera rigurosamente este principio, se requeriría que todos los nombramientos para las magistraturas supremas ejecutiva, legislativa y judicial procedan de la misma fuente de autoridad, el pueblo, a través de canales que no tengan comunicación alguna entre sí..." (Madison,1788, "The Structure of the Government Must...").

104 No hay sólo un centro de extracción/designación como el parlamentario (de mayorías hegemónicas), sino que las mayorías hegemónicas aún pueden quedar más reforzadas al 
También actualmente todos los organismos de control -sin siquiera visualización constitucional-, y bajo el eufemismo de "administraciones independientes" (organismos de vigilancia financiera, organismos de control en la prestación de servicios públicos básicos, organismos de fiscalización del comercio armamentístico, etc.) son designados directa o indirectamente por la mayoría hegemónica, a través de los gobiernos. Organismos con funciones de control y fiscalización de importancia sobresaliente en relación a soberanía o derechos humanos ${ }^{105}$.

- El sistema actual de extracción dual legislativo-ejecutivo tiene una agravante añadida, que se deduce del anterior apartado: se hace bajo unos criterios que eluden la proporcionalidad de las cámaras -ya de por sí desproporcionales- optando por un método de "cupo electoral" (mayoría cualificada) bipartidista.

Partiendo del cuestionable supuesto de cómo dichas instituciones de control tienen que ser sólo emanación de la (representación) de la soberanía (parlamentaria) cabría llevar esta premisa hasta sus últimas consecuencias y, por lo tanto, proponer que los miembros de tales instituciones y organismos (colegiados/pluripersonales) fueran designados en función de la proporcionalidad de las fuerzas parlamentarias ("parlamentarismo extractivo proporcional") ${ }^{106}$. De esta manera se eliminarían los sistemas de mayorías/mayorías de cualificación para evitar su práctico monopolio por parte de los dos partidos hegemónicos. En el caso de un sistema con representación proporcional pura se debería aumentar el número de componentes de dichos órganos para dar acceso a un porcentaje más alto de partidos representados.

El sistema tendría dos ventajas conexas, además de la principal ya mencionada:

intervenir en las designaciones la jefatura del Estado o los gobiernos (Estados Unidos, Reino Unido, Francia, Italia o Alemania). Véase el caso del propio poder judicial en los casos de Estados Unidos, Reino Unido o Francia, con la colaboración cromada del ministro de justicia, de un comité del senado o de su majestad real (en este sentido, vid., Palacios, 2011, "El mito de la separación del poder judicial en el constitucionalismo clásico...").

${ }^{105}$ Lo que en el caso español serían la Comisión nacional de los mercados y la competencia, Comisión nacional del mercado de valores, Junta interministerial para el comercio y control del material de defensa y tecnologías de doble uso, o, incluso, donde se podría integrar espacios administrativos "independientes" como el Tribunal administrativo central de recursos contractuales (Palacios, 2014, "Del proceso destituyente...").

${ }_{106}$ Dejando al margen a las instituciones unipersonales, como la Defensoría del Pueblo que podría ser elegido por sistema directo de elección popular. 
a) La representación en dichas instituciones tendría mayor "capacidad de control" (check) al no estar cartelizado por una lógica bipartidista; b) la sustitución y toma de posesión sería puntual y automática una vez terminado el mandato de la institución correspondiente, con lo cual se favorecería un espacio de gobernabilidad, es decir de "equilibrio y funcionalidad inmediata" ("balance"). Lo contrario ha podido llevar a: 1) un quebrantamiento constitucional severo por estar ejerciendo tareas sustanciales una institución caducada, que no se corresponde con la correlación representativa de un nuevo parlamento, por lo que estamos ante una directa usurpación de poder ${ }^{107}$; 2) una añadida disfuncionalidad estructural dentro de ámbitos institucionales generales ${ }^{108}$.

\section{CONCLUSIÓN}

Una sola: defensa del principio constitucional -primero- de igualdad o "no discriminación". Focalizado en el ámbito más central de una democracia: la representación. A través del voto igual.

Históricamente superada la ruptura formal del principio de igualdad en raza, credo, género o riqueza, no es asumible que reste la discriminación -ex post facto- de tipo ideológico.

La proporcionalidad pura puede ser funcional: institucionaliza la diversidad y coadyuva a la resolución concertada del conflicto. El Derecho Constitucional posee mecanismos de adaptación y desarrollo para la recepción plural proporcional a través de técnicas de coalición, presupuestos de consenso y, llegado el caso, de parlamentarismo funcional.

\footnotetext{
${ }^{107}$ Al tiempo de escribir estas líneas sirva de ejemplo la actual "no renovación" del Consejo General del Poder Judicial. Actualmente en mora de más de dos años, lo que constituye un directo quebrantamiento constitucional. Durante estos dos años dicha institución ha seguido efectuando sesenta y ocho nombramientos de jueces de alta responsabilidad entre los que destacan dieciocho magistrados del Tribunal Supremo, tres en la Audiencia Nacional, veinticuatro en los tribunales superiores autonómicos y veintitrés en audiencias provinciales.

${ }^{108}$ Fundamentalmente en el poder judicial. Sirva de ejemplo las consecuencias de la actual modificación (en trámite) de la LOPJ ("Proposición de Ley orgánica por la que se modifica la Ley orgánica del poder judicial, para el establecimiento del régimen jurídico aplicable al Consejo general del poder judicial en funciones") para impedir nombramientos del CGPJ (Constitucional, Supremo, y presidentes de Superiores, Audiencia y Sala), cuando este se encuentre en funciones; reforma susceptible de paralizar decenas de nombramientos y, por lo tanto, el funcionamiento ordinario de dichas salas.
} 
La discriminación representativa ha sido argumento de sesgo culturalplutocrático con el que ha convivido la historia constitucional para amparar el constructo falaz de "gobernabilidad", como una técnica ideológica para el quebrantamiento democrático-social.

En esta nueva época, donde el telos económico-financiero está logrando sobre-imperar en la polis y penetrar el ágora, -donde se apela con mayor extremosidad al gobierno de pocos- se haría conveniente la recepción proporcional institucional pura de la sociedad civil popular, ante su creciente abandono, desasosiego y desafección (Tu ne cede malis, sed contra audentior ito). Antes de una impugnación global radical del sistema.

\section{BIBLIOGRAFÍA Y DOCUMENTACIÓN}

- AIReF, 2019, Evaluación del gasto público 2019. Estudio beneficios fiscales (http://www.airef.es/).

- ARBÓS, X. \& GINER S., 1993, La gobernabilidad. Ciudadanía y democracia en la encrucijada mundial, Siglo XXI, Madrid.

- BASTIDA FREIJEDO, F., 2001, "De nuevo sobre el modo de designación de los presidentes autonómicos y la forma de gobierno en Parlamento y Constitución", Anuario de las Cortes de Castilla-La Mancha, ํㅡ 5.

- BBVA Research, 2016, Situación España. Cuarto trimestre 2016 (https://www.bbvaresearch.com/publicaciones/situacion-espana-cuartotrimestre-2016/).

- BERNABÉ MARCHENA, D., 2018, La trampa de la diversidad, Akal, Madrid.

- BRINTON, C., 1962, Anatomía de la Revolución, Aguilar, Madrid.

- BROWNE, E. \& FRANKLIN, M., 1973, "Aspects of Coalition Payoffs in European Parliamentary Democracies", American Political Science Review, v. $67, \mathrm{n}^{\circ} 2$.

- CASTELLS OLIVÁN, M., 2012, Redes de indignación y esperanza. Los movimientos sociales en la era de internet, Alianza, Madrid. 
- CLAVERO SALVADOR, B., 1984, Evolución Histórica del Constitucionalismo Español, Tecnos, Madrid.

- Comisión Europea, 2014, Informe de la comisión al consejo y al parlamento europeo. informe sobre la lucha contra la corrupción en la UE (COM, 2014, 38).

- Congreso de los Diputados (Bocg), proposiciones de ley 2 de febrero de 2021 Núm. 137-4, "Proposición de Ley Orgánica por la que se modifica la Ley Orgánica 6/1985, de 1 de julio, del Poder Judicial, para el establecimiento del régimen jurídico aplicable al Consejo General del Poder Judicial en funciones".

- Consejo de la Unión Europea, 2002, "Decisión marco sobre la lucha contra el terrorismo" (2002/475/JAI), de 13 de junio de 2002 (https://eurlex.europa.eu/legal-content/ES/ALL/?uri=celex\%3A32002F0475).

- COSER, L. A., 1970, Nuevos aportes a la teoría del conflicto social, Amorrortu, Buenos Aires.

- DE CABO MARTíN, C., 1986, La crisis del Estado social, PPU, Barcelona.

- DE VEGA GARCÍA, 1998, "Mundialización y Derecho constitucional. La crisis del principio democrático en el constitucionalismo actual", Revista de Estudios Políticos, no. 100.

- DE VERGOTTINI, G., 1985, Derecho constitucional comparado, Espasa Calpe, Madrid.

- Democracia Real Ya, 2011, Manifiesto (http://www.democraciarealya.org.es/manifiesto-comun/).

- DUVERGER, M., 1967, La democracia sin el pueblo, Ariel, Barcelona.

- ESTEFANÍA MOREIRA, J., 2000, El poder en el mundo, Plaza \& Janés, Madrid.

- FERRAJOLI, L. \& ZOLO, D., 1980, Democracia autoritaria y capitalismo maduro, El Viejo Topo, Barcelona.

- FERRAJOLI, L., 2011, Poderes salvajes. La crisis de la democracia constitucional, Trotta, Madrid. 
- FLISFISCH, A., 1989, "Gobernabilidad y consolidación democrática: sugerencias para la discusión", Revista Mexicana de Sociología, Vol. 51, no. 3.

- FOUCAULT, M., 2004, Sécurité, territoire, population, Éditions du Seuil, Paris.

- FUSILIER R., 1960, Les Monarchies Parlementaires, Étude Sur Les Systèmes De Gouvernement, Les Éditions Ouvrières, Paris.

- GALBRAITH, J K., 2013, El Crash de 1929, Ariel, Barcelona

- GAMSON, W., 1961, "A Theory of Coalition Formation". American Sociological Review, Vol. 26, ํㅡ. 3.

- GITLIN, T., 2012, Occupy Nation: The Roots, the Spirit, and the Promise of Occupy Wall Street, It Books, New York.

- GONZÁleZ CASANOVA, J. A., 1984, Teoría del Estado y Derecho Constitucional, Vicens, Barcelona.

- GUNTHER, R. \& SANI, G. \& SHABAD, G., 1986, El sistema de partidos políticos en España. Génesis y evolución, C.I.S., Madrid.

- HABERMAS, J., 1981, Historia y crítica de la Opinión Pública, Gustavo Gili, Barcelona.

- HELLER, H., 1996, El sentido de la política y otros ensayos, Pre-textos, Valencia.

- 2004, Teoría del Estado, Comares, Granada.

- HESSEL, S., 2010, indignaos! Un alegato contra la indiferencia y a favor de la insurrección pacífica.

- HUNTINGTON, S., CROZIER, M., WATANUKI, J., 1975, The Crisis of Democracy. Report on the governability of democracies to the Trilateral Commissión, New York University Pres, New York.

- IRUSTA, A., 2014, "El concepto de gubernamentalidad. La economización de la política y el problema del Estado en Michel Foucault", en Philosophia, $\begin{array}{llll}\text { no } & 74 & \text { (2), } & \text { 39-59 }\end{array}$

(https://bdigital.uncu.edu.ar/app/navegador/?idobjeto=3034).

- JUDT, T., 2010, Algo va mal, Taurus, Madrid. 
- KIRCHHEIMER, O., 1969, Politics, Law, and Social Change (Selected Essays), Columbia University Press, New York.

- KLEIN, N., 2007, La doctrina del shock, Paidós, Barcelona.

- KÜHNL, R., 1991, La República de Weimar: establecimiento, estructuras y destrucción de una democracia, Institució Valenciana d'Estudis i Investigació, Valencia.

- La Información, 2011, "Bélgica: 500 días sin Gobierno y mejora en paro, PIB, déficit y salario mínimo" (https://www.lainformacion.com/economianegocios-y-finanzas/belgica-500-dias-sin-gobierno-y-mejora-en-paro-pibdeficit-y-salario-minimo_XqgcLwQO0YO6X5B76vnYl6/).

- La Sexta.com/Europa Press, 2019, "Carmen Calvo descarta el Gobierno de coalición y pide a Unidas Podemos que apoye un programa' de medidas" (https://www.lasexta.com/noticias/nacional/carmen-calvo-descartagobierno-coalicion-pide-unidas-podemos-que-apoye-programamedidas_201909025d6cd45f0cf213a78c60b178.html).

- La Vanguardia, 7/4/2021, "Casado, P.: El multipartidismo es lo peor que ha pasado en diez años" (https://www.lavanguardia.com/politica/20210406/6629804/casado.html)

- LEMM, V. (coord.), 2010, Michel Foucault: Neoliberalismo y biopolítica, UDP, Santiago de Chile.

- Libre Mercado, 2018, "Se repite la historia de Bélgica y España: Alemania, crecimiento récord en 100 días sin gobierno" (https://www.libremercado.com/2018-01-18/se-repite-la-historia-de-belgicay-espana-alemania-crecimiento-record-en-100-dias-sin-gobierno1276612248/).

- LIJPHARDT, A., 1985, "The field of electoral systems rearch: a critical survey”, Electoral Studies, vol. 4, ㄲo1.

- 1994, Sistemas electorales y sistemas de partidos, C.E.P.C., Madrid.

- MADISON, J., 1788, "The Structure of the Government Must Furnish the Proper Checks and Balances Between the Different Departments", Federalist, $n^{\circ}$ 51, Library of Congress. Federalist Papers: Primary Documents in American History (https://guides.loc.gov/federalistpapers/text-51-60). 
- MARTíN SECO, J., 2020, Una historia insólita. El gobierno Frankenstein, El Viejo Topo, Barcelona.

- MAYER, N. \& PERRINEAU, P. (dir.), 1989, Le Front National a decouvert, Presses de la Fondation Nationale des Sciences Politiques, París.

- MICHELS, R., 2008, Los partidos políticos. Un estudio sociológico de las tendencias oligárquicas de la democracia moderna, Amorrortu, Buenos Aires.

- Ministère de L'interiéur, 2017 (https://www.interieur.gouv.fr/Elections/Lesresultats/Legislatives/elecresult_legislatives-2017/(path)/legislatives2017//).

- Ministerio de Hacienda, 2019, Orden HAC/973/2019, de 26 de septiembre, por la que se fijan las cantidades de las subvenciones a los gastos originados por actividades electorales para las elecciones generales de 10 de noviembre de 2019.

- MONEDERO FERNÁNDEZ, J. C., 2012, Dormíamos y despertamos. El 15$M$, la reinvención de la democracia, Nueva Utopía, Madrid.

- MONEREO PÉREZ, M., (coord.), 2018, Proceso constituyente y cambio constitucional para la España del siglo XXI, EI Viejo Topo, Barcelona.

- MONGE LASIERRA, C., 2017, 15-M. Un movimiento político para democratizar la sociedad, Prensas Universidad de Zaragoza.

- Occupy Wall Street, 2011, en (http://www.occupywallst.org/).

- One man, one vote (https://en.wikipedia.org/wiki/One_man,_one_vote).

- PAlacios ROMEO, F., 1998 a, La Civilización de choque. Hegemonía occidental, modernización y Estado periférico, Centro de Estudios Constitucionales, Madrid.

- 1998 b, "Liberalismo y derechos virtuales. Apuntes para una Teoría del Estado en su continuum histórico", Revista Mexicana de Ciencias Políticas y Sociales, no 173, Facultad de Ciencias Políticas y Sociales, Universidad Nacional Autónoma de México, México D.F.

- 2011, "El mito de la separación del poder judicial en el constitucionalismo clásico y la nueva configuración participativa en Latinoamérica En torno a una aporía del constitucionalismo clásico: 
Quis custodiet ipsos custodes", en Revista General de Derecho Público Comparado no 9, lustel, pp. 1-40.

- 2014, "Del proceso destituyente al debate constituyente. 10 elementos para una democracia radical", Teoría y práctica del poder constituyente" (R. Martínez Dalmau, ed.), Tirant Lo Blanch, Valencia.

- 2016, "La lucha por la Constitución: una dialéctica entre Ágora y Fórum (con epítome sobre nuevo constitucionalismo latinoamericano)", en Constitucionalismo crítico. Liber amicorum Carlos de Cabo Martín (García Herrera, M., Asensi, J. y Balaguer, F., coords.), Tirant Lo Blanch, Valencia.

- 2017, "La reformulación del Estado en la historia constitucional de Venezuela: en torno al concepto de seguridad social integral en la Constitución de 1999" en Un siglo de constitucionalismo en América Latina 1917-2017 (Andrews C., coord.), CIDE / Secretaría de Relaciones Exteriores de México, México D. F.

- 2018, "Democracia, Representación y Sistema Electoral, una histórica difícil empatía bajo lógica de control hegemónico", en Palacios y Cebrián (eds.), Elegir cómo elegir. Retos y urgencias del régimen electoral en España, Fundación Giménez Abad, Zaragoza.

- PALACIOS ROMEO, F. \& 15-M/Huesca, 2011, "Mecanismos de control, transparencia y pluralismo de la misma estructura representativopartitocrática y del Estado en general" (http://acampadahuesca.blogspot.com/2011/12/las-politicas-liberalessuponen-la.html).

- PARKINSON, H., 1970, Winning Your Campaign: A Nuts-and-Bolts Guide to Political Victory. Prentice Hall, New Jersey.

- Parliament of the United Kingdom, 2001. Crime and Security Act (https://www.legislation.gov.uk/ukpga/2001/24/contents).

- PASTOR VERDÚ, J., 2002, Qué son los movimientos antiglobalización, R.B.A, Barcelona.

- PERRINEAU, P., 2000, Les Croisés de la société fermée: les extrêmes droites en Europe, éditions de l'Aube, La Tour d'Aigues. 
- 2003, Le Désenchantement démocratique, éditions de l'Aube, La Tour d'Aigues.

- PORRAS NADALES, A., 1988, Introducción a una teoría del Estado postsocial, PPU, Barcelona.

- ROSANVALLON, P., 2006, La contré-démocratie. La politique á l'age de la défiance, Éditions du Seuil, París.

- ROSE, R., 1983, "En torno a las opciones en los sistemas electorales: alternativas políticas y técnicas", Revista de Estudios Políticos, №. 34.

- SÁENZ ROYO, E., 2012, "Parlamento, partidos y Estado autonómico: sobre la conveniencia de suprimir el Senado", Revista de Derecho Político, núm. 85.

- Secretaría de Estado de Presupuestos y Gastos, Estadísticas 2011-2019 Prorrogado Presupuestos Generales del Estado Consolidados 2020, en https://www.sepg.pap.hacienda.gob.es/sitios/sepg/es-

ES/Presupuestos/DocumentacionEstadisticas/Estadisticas/Paginas/Estadist icas.aspx).

- SOREL, G., 1976, Reflexiones sobre la violencia, Alianza, Madrid.

- SORIANO MORENO, S., 2018, "El sistema electoral del Congreso de los diputados: análisis, proporcionalidad y propuestas de mejora", en Palacios, F. y Cebrián, E., Elegir cómo elegir. Retos y urgencias del régimen electoral en España, Fundación Giménez Abad, Zaragoza.

- STIGLITZ, J., 2003, Los felices 90. La semilla de la destrucción, Santillana, Madrid.

- SUBIRATS HUMET, J., 2011, Otra sociedad, ¿otra política?, Icaria, Barcelona, 2011.

- TAIBO ARIAS, C., 2005, Movimientos de resistencia frente a la globalización capitalista. Ediciones B, Barcelona.

- 2011, Nada será como antes. Sobre el movimiento 15-M, Los Libros de la Catarata, Madrid.

- UiO, Global Surveillance, Universitetsbiblioteket (https://www.ub.uio.no/fag/naturvitenskapteknologi/informatikk/faglig/bibliografier/no21984.html). 
fundación

Manuel Giménez Abad

deEstudios Parlamentariosy delEstado Autonómico

- United States Congress, 2001, USA Patriot Act, Uniting and Strengthening America by Providing Appropriate Tools Required to Intercept and Obstruct Terrorism

(https://bja.ojp.gov/program/it/privacy-civilliberties/authorities/statutes/1281).

- VALLES J., 1986, "Sistema electoral y democracia representativa", Revista de Estudios Políticos, ํo 53.

- WARWICK, P., \& DRUCKMAN, J., 2005, "The missing piece: Measuring portfolio salience in Western European parliamentary democracies", en European Journal of Political Research, no 44. 